\title{
QUEEN'S
UNIVERSITY
BELFAST
}

\section{In vitro - in vivo relations for the parenteral liposomal formulation of Amphotericin B: A clinically relevant approach with PBPK modeling}

Díaz de León-Ortega, R., D'Arcy, D., Lamprou, D., \& Fotaki, N. (2020). In vitro - in vivo relations for the parenteral liposomal formulation of Amphotericin B: A clinically relevant approach with PBPK modeling. European Journal of Pharmaceutics and Biopharmaceutics. https://doi.org/10.1016/j.ejpb.2020.03.001

Published in:

European Journal of Pharmaceutics and Biopharmaceutics

Document Version:

Peer reviewed version

Queen's University Belfast - Research Portal:

Link to publication record in Queen's University Belfast Research Portal

\section{Publisher rights}

Copyright 2020 Elsevier.

This manuscript is distributed under a Creative Commons Attribution-NonCommercial-NoDerivs License

(https://creativecommons.org/licenses/by-nc-nd/4.0/), which permits distribution and reproduction for non-commercial purposes, provided the author and source are cited.

\section{General rights}

Copyright for the publications made accessible via the Queen's University Belfast Research Portal is retained by the author(s) and / or other copyright owners and it is a condition of accessing these publications that users recognise and abide by the legal requirements associated with these rights.

Take down policy

The Research Portal is Queen's institutional repository that provides access to Queen's research output. Every effort has been made to ensure that content in the Research Portal does not infringe any person's rights, or applicable UK laws. If you discover content in the Research Portal that you believe breaches copyright or violates any law, please contact openaccess@qub.ac.uk. 


\section{European Journal of Pharmaceutics and Biopharmaceutics}

\section{In vitro - in vivo relations for the parenteral liposomal formulation of Amphotericin $B$. Part 2: A clinically relevant approach with PBPK modeling \\ --Manuscript Draft--}

\begin{tabular}{|c|c|}
\hline Manuscript Number: & EJPB_2019_1118R1 \\
\hline Article Type: & Research Paper \\
\hline Keywords: & $\begin{array}{l}\text { PBPK-PD; Amphotericin B; in vitro release; liposomes; clinically relevant; PBPK } \\
\text { modeling }\end{array}$ \\
\hline Corresponding Author: & $\begin{array}{l}\text { Nikoletta Fotaki } \\
\text { University of Bath } \\
\text { Bath, Somerset UNITED KINGDOM }\end{array}$ \\
\hline First Author: & Ricardo Díaz de León-Ortega \\
\hline \multirow[t]{4}{*}{ Order of Authors: } & Ricardo Díaz de León-Ortega \\
\hline & Deirdre D'Arcy \\
\hline & Dimitrios Lamprou \\
\hline & Nikoletta Fotaki \\
\hline Abstract: & $\begin{array}{l}\text { In vitro release testing is a useful tool for the quality control of controlled release } \\
\text { parenteral formulations, but in vitro release test conditions that reflect or are able to } \\
\text { predict the in vivo performance are advantageous. Therefore, it is important to } \\
\text { investigate the factors that could affect drug release from formulations and relate them } \\
\text { to in vivo performance. In this study the effect of media composition including albumin } \\
\text { presence, type of buffer and hydrodynamics on drug release were evaluated on a } \\
\text { liposomal Amphotericin B formulation (Ambisome } \AA \text { ). A physiologically based } \\
\text { pharmacokinetic (PBPK) model was developed using plasma concentration profiles } \\
\text { from healthy subjects, in order to investigate the impact of each variable from the in } \\
\text { vitro release tests on the prediction of the in vivo performance. It was found that } \\
\text { albumin presence was the most important factor for the release of Amphotericin B from } \\
\text { Ambisome } ® ; \text { both hydrodynamics setups, coupled with the PBPK model, had } \\
\text { comparable predictive ability for simulating in vivo plasma concentration profiles. The } \\
\text { PBPK model was extrapolated to a hypothetical hypoalbuminaemic population and the } \\
\text { Amphotericin B plasma concentration and its activity against fungal cells were } \\
\text { simulated. Selected in vitro release tests for these controlled release parenteral } \\
\text { formulations were able to predict the in vivo AmB exposure, and this PBPK driven } \\
\text { approach to release test development could benefit development of such formulations. }\end{array}$ \\
\hline \multirow[t]{5}{*}{ Suggested Reviewers: } & $\begin{array}{l}\text { Filippos Kesisoglou } \\
\text { filippos_kesisoglou@merck.com } \\
\text { Expert in Biopharmaceutics }\end{array}$ \\
\hline & $\begin{array}{l}\text { Brendan Griffin } \\
\text { Brendan.Griffin@ucc.ie } \\
\text { Expert in Biopharmaceutics }\end{array}$ \\
\hline & $\begin{array}{l}\text { Edmund Kostewicz } \\
\text { kostewicz@em.uni-frankfurt.de } \\
\text { Expert in Biopharmaceutics }\end{array}$ \\
\hline & $\begin{array}{l}\text { Maria Vertzoni } \\
\text { vertzoni@pharm.uoa.gr } \\
\text { Expert in Biopharmaceutics }\end{array}$ \\
\hline & $\begin{array}{l}\text { Xujin Lu } \\
\text { xujin.lu@bms.com } \\
\text { Expert in in vitro release studies }\end{array}$ \\
\hline \multicolumn{2}{|l|}{ Opposed Reviewers: } \\
\hline Response to Reviewers: & \\
\hline
\end{tabular}




\section{Dr. Nikoletta Fotaki}

Department of Pharmacy \& Pharmacology

Claverton Down

Bath, BA2 7AY

Tel. +44.1225.386728; fax +44.1225.386114

Email: n.fotaki@bath.ac.uk

http://www.bath.ac.uk/pharmacy/contacts/academics/nikoletta fotaki/

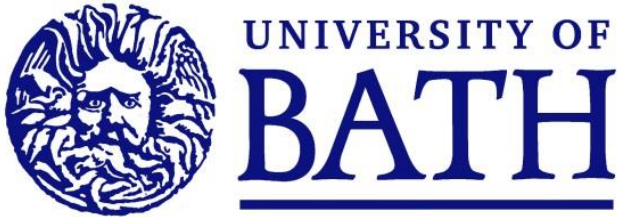

February 20, 2020

Dear Professor Goepferich,

Please accept the revised version of the original research manuscript on "In vitro in vivo relations for the parenteral liposomal formulation of Amphotericin B. Part 2: A clinically relevant approach with PBPK modeling". The reviewer's comments have been addressed and the manuscript has been revised accordingly.

Thank you for considering our manuscript.

Sincerely yours,

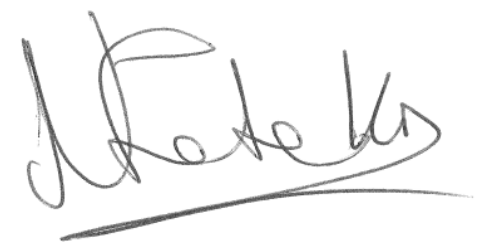

Dr Nikoletta Fotaki 
We would like to thank the reviewer for his valuable comments and suggestions. Please find below our reply to each comment and the indication of the changes made to the manuscript (highlighted in yellow) to address reviewer's suggestions.

Editor and Reviewer comments:

Reviewer \#1: The manuscript by Díaz de León-Ortega investigates the effect of media composition including albumin presence, type of buffer and hydrodynamics on drug release of a liposomal Amphotericin B formulation (Ambisome ${ }^{\circledR}$ ). A physiologically based pharmacokinetic (PBPK) model was developed using plasma concentration profiles from healthy subjects, in order to investigate the impact of each variable from the in vitro release tests on the prediction of the in vivo performance.

Strengths:

1. Physiologically based pharmacokinetics (PBPK) modeling is quite an important approach in predicting the in vivo disposition of drug compounds prior to its actual administration to animals and/or humans. These predictions are quite valuable and useful in helping to determine the dosing regimen that would elicit the optimal efficacy/toxicity ratio (therapeutic index) for any such drug compounds. PBPK modeling can be very valuable when drug compounds are administered into a diseased population where blood flow, plasma protein and lipoprotein concentrations and tissue permeability may be altered compared to a non-disease state. Thus, the premise of this study is sound and appropriate.

2. Limitations and Considerations:

The authors have decided to investigate liposomal Amphotericin B (Ambisome ${ }^{\circledR}$ ) as a model compound to determine the impact of different variables from the in vitro release tests (i.e. effect of media composition including albumin presence, type of buffer and hydrodynamics) on the prediction of in vivo performance. Since amphotericin B (AmB) is quite a unique molecule with minimal aqueous and lipid solubility (it is amphoteric), high plasma protein and lipoprotein association and liposomal amphotericin B is an unusual drug delivery formulation I am not sure it is the best choice to investigate the utility of PBPK modeling particularly as it is related to AmB plasma concentrations.

RESPONSE: We would like to express our appreciation to the reviewer in taking the time to study our manuscript and present a such comprehensive picture of the issues impacting a PBPK analysis of AmB and its formulations. We have answered the more specific comments below and indicated, where relevant, any changes to the manuscript.

In the first instance, we feel that it is important to clarify that the aim of the current study was not to present a comprehensive PBPK model of AmB concentrations following administration of the liposomal formulation, improving on models already available in the literature; our aim was to present a relatively high level PBPK model of a liposomal formulation in conjunction with in vitro release data, to illustrate the application of PBPK 
modeling as a tool to guide the development of in vitro performance testing of liposomal preparations, using liposomal AmB as a model formulation. Furthermore, in this study our goal was also to determine the effects of various in vitro release conditions (e.g. albumin concentration) on in vitro release, and how this may translate into systemic bioavailability (explored using in vitro microbiology methods). Obviously, it was necessary to select a model formulation from the few commercially available liposomal preparations with sufficient in vivo data available in the literature. Thus, the site of action of AmB specifically is not of central relevance to this study.

To this end, we have added emphasis to the meaning of the term "clinically relevant dissolution" (pg 3 line 46). We have also clarified that the relationship between microbial killing and PK profile is a general one rather than being interpreted as being specific to AmB (pg 4 line 77). The aim of the study has been revised accordingly in order to clarify that the PBPK/PD model is relevant to fungal infections in plasma (i.e. fungaemia) (pg 5 line 98). We would like also to note that the approximations and limitations to the PBPK/PD model are described in detail in section 3.5, and that the PBPK-PD results are presented as an illustration of the potential for use of in vitro release data and suitable microbiology data in combination with a PBPK-PD model in order to guide parenteral formulation development based on pharmacodynamic outcomes.

Below are a few issues you need to consider when using PBPK modeling for any amphotericin B formulation:

a. AmB is a membrane disruptor that binds to the sterol component of cells; cholesterol which is the main sterol component of mammalian cells and ergosterol which is the main sterol component of fungal cells. It is the free monomeric form of AmB that elicits its biological effect at the cellular level by binding to the sterol component of the cell membrane, disrupting the membrane's integrity leading to cell lysis.

b. AmB efficacy and toxicity is determined by AmB tissue concentrations (and not plasma concentrations) and the availability of the AmB free monomeric form within these tissues (tissues that a free of the fungal infection and those that contain the fungal infection).

RESPONSE: Thank you for your comment. In line with our point above, we are using liposomal $\mathrm{AmB}$ as a model drug, to investigate the use of PBPK modeling in the development of in vitro release tests. Our study is focussed on plasma concentrations (though using a similar approach release tests could be developed to be relevant to release in other tissues, and aligned with concentrations of free drug in those other tissues, if such concentration data was available). For many drugs, including antimicrobials, the site of infection is not the blood or plasma, but blood/plasma concentrations are used as a proxy measure for concentrations at the site of action. The use of such concentrations as a proxy measure is more complex for liposomal preparations (in concordance with the details supplied by the reviewer). For this reason, we limited our focus to release from liposomal AmB in the plasma, as a model liposomal drug formulation.

c. AmB is tightly associated with the phospholipid components of the liposome and is only released as a free monomeric form in the following manner: 
i. when plasma proteins (like albumin) shear the integrity/structure of the liposome within the circulation it may release free AmB-however, since AmB has very limited aqueous and lipid solubility immediately upon release $A m B$ is highly bound to plasma proteins (i.e. albumin, alpha-1-glycoprotein), lipoproteins (particularly LDL and VLDL) and Red Blood Cells causing RBC hemolysis.

ii. when fungal phospholipases are secreted from fungal cells that cohabitate in the RES tissues (i.e. liver, spleen, kidney and lung) disrupting the structural integrity of the liposome and releasing free AmB. AmB is then free to bind to the sterol components of fungal cells and mammalian cells leading to cell lysis.

d. There have been a number of studies previously publish that report the lipoprotein association (particularly HDL) of AmB following administration and/or coincubation of liposomal amphotericin $B$ into the systemic circulation and plasma respectively.

Thus any in-depth PBPK modeling of liposomal amphotericin B would need to take into consideration the following additional parameters: red blood cell binding, alpha-1glycoprotein binding, lipoprotein association, hypo and hyer-lipidemia, tissue biodistribution, tissue fungal load, fungal phospholipase concentration. *Note liposomal amphotericin B is administered to the bloodstream and not the plasma stream and thus blood components i.e. complement proteins and RBCs need to be considered in any in vitro/in vivo correlation.

Therefore although the correlations are interesting, the results are not unexpected; e.g. the PK profiles for AmB within the liposome vs. released $A m B$ and the influence of increasing concentrations of albumin on the release of AmB from the liposome. Furthermore, AmB systemic exposure although interesting is not clinically relevant when it comes to pharmacological effect. AmB tissue concentrations and exposure are the key to the efficacy/toxicity ratio of AmB and using a PBPK model to investigate this would have been much more useful.

RESPONSE: Notwithstanding all of the valid points made by the reviewer concerning the release and binding characteristics of AmB, the literature data on which our PBPK model was based consisted of plasma concentration data. We are aware of the binding tendencies of AmB with lipoproteins, but as albumin is the most prevalent plasma protein we consider it the most relevant for a highly protein-bound drug such as AmB for the exploration of in vitro release test development.

A PBPK model can always be further developed to include greater detail and model various processes with greater precision. The binding of AmB to alpha-1 acid glycoprotein and lipoprotein beta are already included in the PBPK model presented in our study. Binding to blood components was not included, but as immune-mediated removal from plasma is included as a general umbrella term for e.g. macrophage removal of liposomes, AmB loss from plasma to red blood cells (RBCs) could have been captured by this immune pathway, or other clearance pathways. We have added a sentence in the revised manuscript, detailing the 
potential to further improve the accuracy of the model through specific modeling of the RBC binding process (pg 19, line 426-429).

However, for the purposes of the current study, using a PBPK model built on data from healthy subjects, modeling effects of other pathologies such as hyperlipidemia or tissue fungal phospholipases on AmB concentrations are beyond the scope of the current study. There is considerable detail already included in section 3.5. "PBPK - PD modeling for the patient (hypoalbuminaemic) population", on the approximations and limitations of the model, and the emphasis of the PBPK-PD model as an illustrative example. We have also added a sentence in the revised manuscript, to note the absence of fungal phospholipase effect in the model (pg 20, line 454-455).

With respect to the reviewer's comment concerning results being "not unexpected", as the reviewer noted, albumin can be involved in release from the liposome. Therefore, the increased release rate in the presence of reduced albumin concentrations in vitro is in fact a notable observation. Furthermore, the point of the article was not solely to demonstrate the effect of albumin on liposome release, but to illustrate how in vitro performance testing methods could be developed to capture the effect of albumin concentration on release, and how a PBPK modeling approach could guide the development of these models.

Modeling tissue AmB concentrations to inform efficacy/toxicity mechanisms is not the subject of this study.

Other changes to the manuscript include:

Pg 19 line 419-422, a sentence is added to clarify why the $A \cup C_{0-24}$ could not be calculated for the high velocity profiles

Page 22 line 493: Amendment to acknowledgements section. 


PAPK modeling of observed in
who data of plasma
concentrations of liposomal
and released Amphotericin B
after Ambisome*
administration to healthy
subjects

\section{Medium components} tested:

- PBS or KRB

- Alburnin

- Ble salts

-Phospholipids

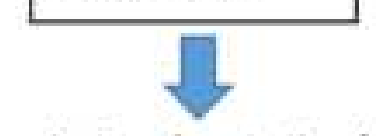

In witro release testing of Ambisome" liposomes

Sample and separate (SS) Continuous flow/dialysis (CFD)

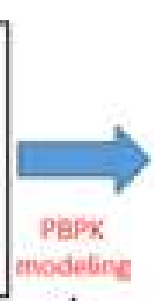

i

1
1
1
1
1

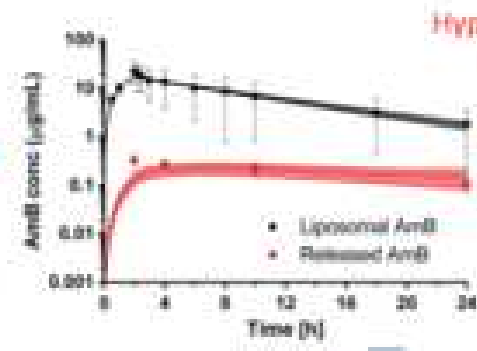

Hrnoafouminaenk popudation
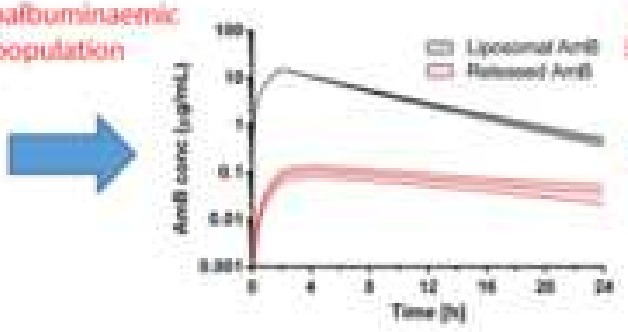

Pupx.PD modelire

Effect on C. abicans

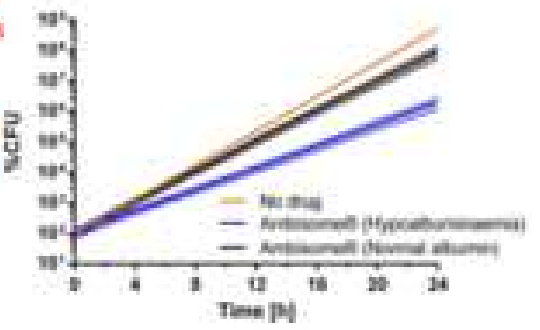

nem $\mathrm{M}$. in vitro release input krel in to profles

Tin witro release

rate constant.

(krekil)
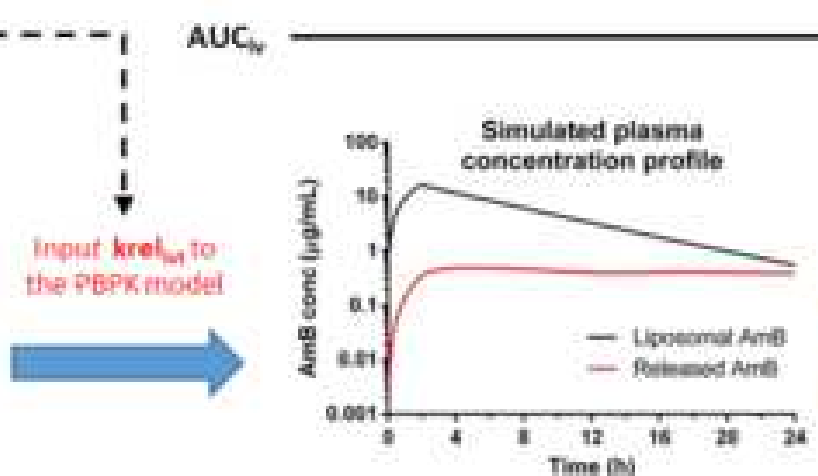

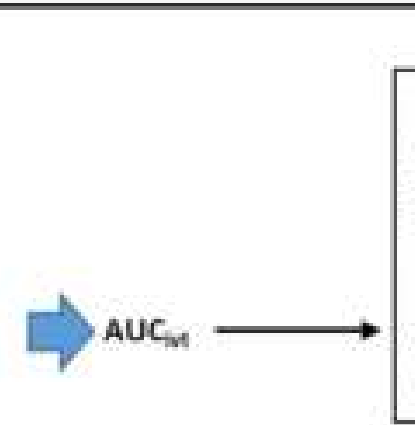

Liposomal Amphotericin A AUC /AUC, similar in media with albumin in $\$ \mathbf{5}$ and with and without albumin in CrO

\section{Released Amphotericin B} AUC, $/ A \cup C_{6}$ similar only in media with albumin in SS and CFD 
1

2

3

4

5

6

1 In vitro in vivo relations for the parenteral liposomal formulation of Amphotericin B. Part 2: A

2 clinically relevant approach with PBPK modeling

3

4 R. Díaz de León-Ortega ${ }^{1}$, D. M. D'Arcy ${ }^{2}$, D.A. Lamprou ${ }^{3}$, N. Fotaki ${ }^{1, *}$

$5{ }^{1}$ Department of Pharmacy and Pharmacology, University of Bath, Bath, United Kingdom

$6 \quad{ }^{2}$ School of Pharmacy and Pharmaceutical Sciences, Trinity College Dublin, Dublin 2, Ireland

$7 \quad{ }^{3}$ School of Pharmacy, Queen's University Belfast, Belfast, United Kingdom

$8 *$ Corresponding Author

9

10 Dr Nikoletta Fotaki

11 Department of Pharmacy and Pharmacology

12 University of Bath

13 Claverton Down

14 Bath, BA2 7AY

15 United Kingdom

16 Tel. +44 1225386728

17 Fax: +44 1225386114

18 E-mail: n.fotaki@bath.ac.uk 


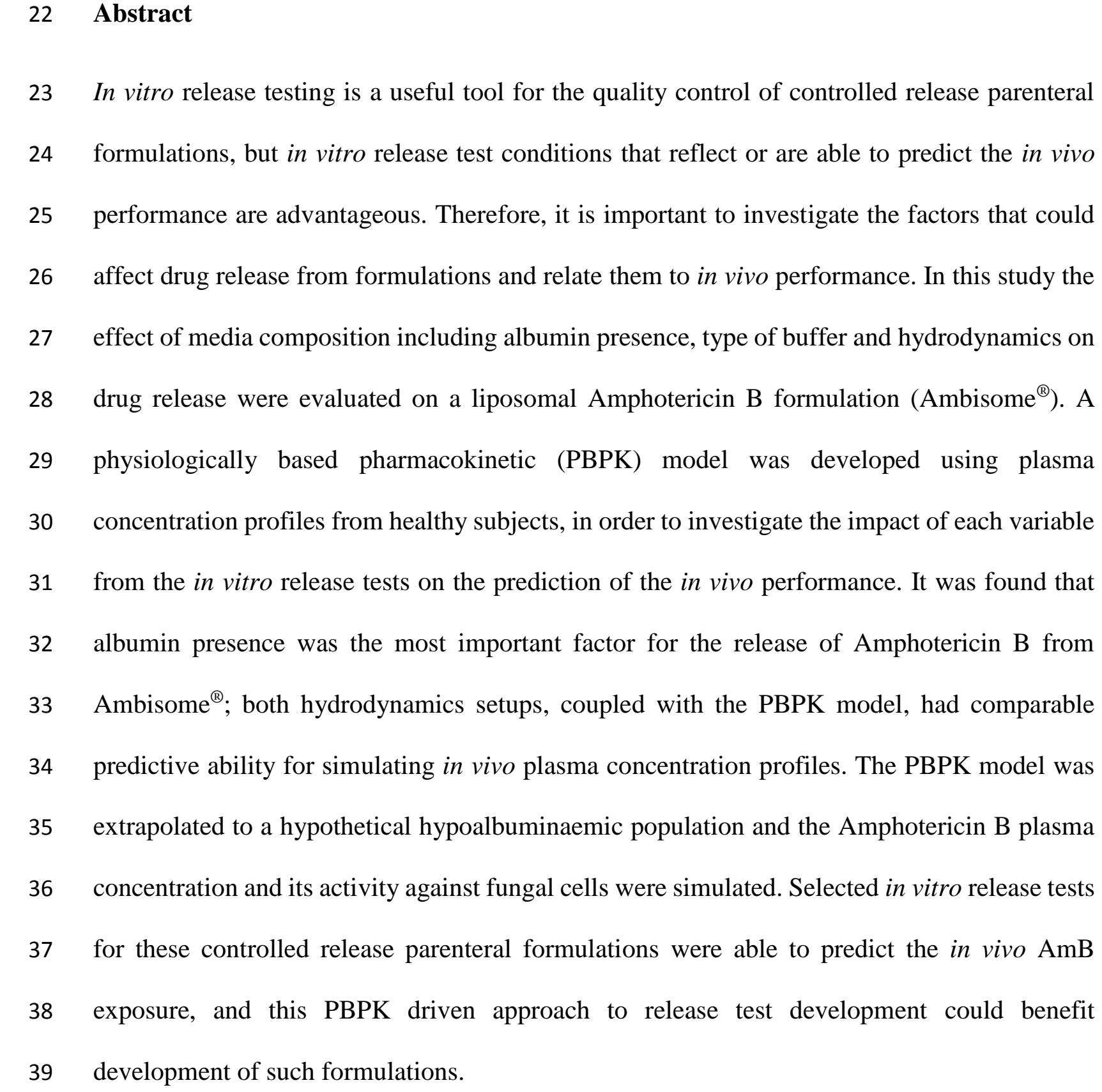

41 Keywords:

42 Amphotericin B; liposomes; PBPK; modeling; in vitro; release; PBPKPD; clinically; relevant 43 


\section{Introduction}

A recent consensus document arising from a workshop dedicated to bringing consistency to terminology used in dissolution testing has defined a clinically relevant in vitro release test as the implication of a link between the in vitro release and the in vivo performance [1]. In order to establish a clinically relevant test, it is important to understand how the test conditions (e.g. media composition and hydrodynamics) affect the in vitro release from the formulation. In some cases, the information obtained from the in vitro release tests is not enough to explain the in vivo behaviour of the formulation and the released drug, and a mechanistic understanding of the in vivo performance is required [2]. This can be achieved by the use of physiologically based pharmacokinetic (PBPK) modeling. The general concept of PBPK modeling is to mathematically describe relevant physiological, physicochemical, and biochemical processes that determine the pharmacokinetic behaviour of a compound [3-5]. PBPK modeling and simulation are currently a trending tendency and commercial software are available (for example, Gastro- Plus ${ }^{\circledR}$, simCYP $^{\circledR}$ or PK-Sim ${ }^{\circledR}$ [6]). PBPK modeling is now accepted by regulatory agencies [7]. The Food and Drug Administration (FDA) have published the "Physiologically Based Pharmacokinetic Analyses — Format and Content (Guidance for Industry) [8]" and the European Medicines Agency (EMA) the "Guideline on the qualification and reporting of physiologically based pharmacokinetic (PBPK) modelling and simulation [9]". A PBPK model can be developed considering 4 stages: i) setting the model equations to represent the system, ii) input data to the model, iii) perform the simulation and iv) model validation (observed vs simulated data, parameter sensitivity analysis) [2]. A sensitivity analysis allows the identification of the parameters that have the greatest influence on the simulation $[10,11]$.

A biopredictive release method consists of in vitro release testing conditions that, coupled with mathematical modeling, are capable of predicting in vivo pharmacokinetic profiles [1]. PBPK 
modeling can be extrapolated to simulate diseased populations, and could thus be used for example for hypoalbuminaemic patients (plasma albumin $<25 \mathrm{~g} / \mathrm{L}$ [12]), in order to investigate the pharmacodynamics (PD) of the drug [13]. Hypoalbuminaemia can be observed in critically ill patients with sepsis, who may be among the patient cohort administered AmB.

PBPK/PD models integrate the movement of the drug in the body with its pharmacological activity [13]. In antimicrobial therapy, the pharmacological effect is the activity against an infectious agent [14-16]. If a PBPK/PD model is used to evaluate the antimicrobial activity, for many antimicrobial agents the microbial killing is considered to be dependent on the PK profile of antimicrobial concentration in plasma $[10,17]$. Amphotericin B (AmB) is a poorly soluble highly protein bound drug used in the treatment of severe systemic fungal disease (e.g. Candida $s p$., Aspergillus $s p .[18,19])$ and is commercially available as parenteral lipid formulations (including the liposomal formulation Ambisome ${ }^{\circledR}$ ) for intravenous administration. The development of PBPK models for Amphotericin B in mice and rats after the administration of Fungizone ${ }^{\circledast}$ (colloidal AmB) and Ambisome ${ }^{\circledR}$ have been reported [20, 21], which showed good predictive performance after being extrapolated to humans. For PBPK modeling of Ambisome ${ }^{\circledR}$, the uptake of particles by macrophage cells in organs like the liver and spleen, were taken into account by using a saturable model. When this model was developed, the authors reported that there was no in vitro AmB release data available and they determined a value from fitting the model to the data with a release rate constant of $0.0035 \mathrm{~h}^{-1}$ (in all the tissues) with an initial rapid release of the $8 \%$ of the dose in humans [20,21].

The aims of this study were i) to investigate how the presence of albumin in clinically relevant media containing physiological surfactants (bile salts - phospholipids) [22]) combined with a biorelevant hydrodynamic environment [23], impacts on the release of AmB from Ambisome ${ }^{\circledR}$; ii) to develop a PBPK model to predict plasma drug concentrations in healthy subjects; iii) coupled with the use of the PBPK model, to guide the development of a biopredictive in vitro 
release test for the liposomal AmB formulation Ambisome ${ }^{\circledR}$; iv) to extrapolate the PBPK model to a hypoalbuminaemic population to build a PBPK/PD model to simulate the pharmacological effect of AmB on fungal cells present in hypoalbuminaemic plasma vs plasma with normal albumin levels.

\section{Materials and Methods}

\subsection{Materials}

AmB analytical standard (87.8\%), methanol (MeOH) high performance liquid chromatography (HPLC) grade, formic acid mass spectrometry grade, Sabouraud dextrose (SBD) broth, $\mathrm{NaOH}$, $\mathrm{MgCl}_{2}, \mathrm{CaCl}_{2}$, and $\mathrm{NaHCO}_{3}$ were obtained from Sigma Aldrich (Germany); AmB API powder (85\%) from Cayman Chemical (USA); bovine serum albumin protease free powder fraction V (BSA), dimethyl sulfoxide (DMSO), dextrose, sodium dodecyl sulphate (SLS), $\mathrm{Na}_{2} \mathrm{HPO}_{4}$, $\mathrm{NaH}_{2} \mathrm{PO}_{4}, \mathrm{KH}_{2} \mathrm{PO}_{4}, \mathrm{NaCl}$ and $\mathrm{KCl}$ from Fisher Scientific (USA); phosphatidylcholine (PL) from egg from Lipoid $\mathrm{GmbH}$ (Ludwigshafen, Germany); sodium taurocholate (BS) from Prodotti Chimici e Alimentaria (Italy); Sabouraud dextrose (SBD) agar was obtained from Oxoid (UK), $25 \mathrm{~mL}$ sterile universal culture tubes were obtained from Sterilin Thermo Scientific (UK); $10 \mu \mathrm{L}$ plastic loops from Microspec (UK); GF/D (pore size $2.7 \mu \mathrm{m}, 25 \mathrm{~mm}$ diameter) and $\mathrm{GF} / \mathrm{F}$ (pore size $0.7 \mu \mathrm{m}, 25 \mathrm{~mm}$ diameter) filters from Whatman (UK); regenerated cellulose (RC) filters $0.45 \mu \mathrm{m} 13 \mathrm{~mm}$ diameter from Cronus (UK); cellulose ester dialysis tubing of $300 \mathrm{kDa}$ MWCO from Spectrum Labs (USA), C18 Sep - Pak ${ }^{\circledR}$ Vac 3cc (500 mg) solid phase extraction (SPE) column from Waters (USA) and Ambisome ${ }^{\circledR}$ liposomal AmB formulation from Gilead (Gilead, UK).

\subsection{Sample treatment of $\mathrm{AmB}$ in release media}

The sample treatment of AmB was described previously [23]. Briefly, the SPE method to separate "liposomal AmB" (AmB still entrapped in the liposome) from "released AmB" (AmB 
released from the liposome) was modified from Egger et al [24]. The SPE column was conditioned with methanol, followed by water. $1.0 \mathrm{~mL}$ of sample was passed through the column and the eluate was collected in a clean vial (liposomal AmB), the column was washed with $2.0 \mathrm{~mL}$ of water and collected in the same tube. $1.0 \mathrm{~mL}$ of methanol was flushed through the column to elute the AmB retained in the column (released AmB). In the case of samples with proteins, proteins were precipitated by adding 2 volumes of methanol to 1 volume of the sample followed by mixing in a vortex mixer, then centrifuged for 10 minutes at $12000 \mathrm{rpm}$ and $5^{\circ} \mathrm{C}$. The supernatant was filtered through a $0.45 \mu \mathrm{m} \mathrm{RC}$ filter before injection to the HPLC.

\subsection{Chromatographic conditions for the analysis of $A m B$ from release media}

The chromatographic method to quantify AmB was described previously [25]. Briefly, AmB was quantified by HPLC analysis using a Hewlett Packard Series 1100 equipped with an auto sampler, temperature regulated column compartment, quaternary pump and diode array detector (DAD detector) (Agilent Technologies). The column was a C18 Waters Sunfire Column (Ireland) $150 \times 46 \mathrm{~mm} 5 \mu \mathrm{m}$. The temperature of the column compartment was set at $25^{\circ} \mathrm{C}$. The mobile phase consisted of formate buffer $50 \mathrm{mM} \mathrm{pH}=3.2: \mathrm{MeOH}(27.5: 72.5, \mathrm{v} / \mathrm{v})$; the flow rate was $1 \mathrm{~mL} / \mathrm{min}$ and analysis was performed with the DAD detector at $\lambda=406 \mathrm{~nm}$. The UV spectrum was recorded from 300 to $450 \mathrm{~nm}$. Quantification of AmB in samples was made based on calibration curves. Freshly prepared standard solutions $(0.5-15 \mu \mathrm{g} / \mathrm{mL})$ in the corresponding medium were prepared by appropriate dilution of a $500 \mu \mathrm{g} / \mathrm{mL}$ stock solution of AmB analytical standard in 1:1 MeOH: DMSO v/v. The limit of detection and the limit of quantification were 0.12 and $0.37 \mu \mathrm{g} / \mathrm{mL}$, respectively.

\subsection{In vitro release studies of $\mathrm{AmB}$ from Ambisome ${ }^{\circledR}$}


The factors investigated for the development of the in vitro release studies were: $i$. the composition of the clinically relevant media with biorelevant surfactants (media AmB solubility value equivalent to that observed in plasma from healthy subjects [22]); media composition factors explored were: type of buffer and BSA concentration, and ii. the hydrodynamic conditions in terms of the apparatus used i.e. sample and separate (bottle/stirrer) or continuous flow (flow through cell apparatus).

Media compositions were PBS BS 19.8 mM PL 7.9 mM and KRB BS 20.0 mM PL 4.0 mM, with and without BSA 4.0\% w/v. Media preparation was as previously described [22]. Briefly, BS were weighed and dissolved in buffer and then PL from a stock solution of $100 \mathrm{mg} / \mathrm{mL}$ in dichloromethane was added. Organic solvents were evaporated with a rotary evaporator set at $40^{\circ} \mathrm{C}$ and attached to a vacuum pump. The pressure was decreased from 650 mbar by steps of 70 mbar every two minutes to 100 mbar, where the pressure was maintained for 10 minutes. When included in the medium, BSA was added after the evaporation of the organic solvents.

\subsubsection{Sample and separate method (bottle/stirrer setup)}

The sample and separate method was described previously [23]. Briefly, Ambisome ${ }^{\circledR}$ powder (0.5 mg AmB) was placed into a $100 \mathrm{~mL}$ glass bottle with $30 \mathrm{~mL}$ of release medium and stirred with a magnetic stirrer at $37^{\circ} \mathrm{C}$. Release studies were performed based on a two-level factorial design of experiments (DoE). The factors investigated (composition of release media and agitation conditions) are shown in Table 1; the combination of all the factors resulted in eight experimental setups.

The agitation rates in the bottle/stirrer setup were selected based on the linear velocity of the stirrer edge, which at $130 \mathrm{rpm}(10.2 \mathrm{~cm} / \mathrm{s})$ is comparable to the linear flow velocities in vein/arteries and at $380 \mathrm{rpm}(29.5 \mathrm{~cm} / \mathrm{s})$ to flow velocities in the aorta [23]. Sampling times were $1,2,4,6,8$, and $12 \mathrm{~h}$ and after sample treatment (SPE and protein precipitation), samples 
were injected to the HPLC and AmB concentration in the samples was determined. All experiments were performed in triplicate.

\subsubsection{Continuous flow (flow through cell apparatus)}

169 The flow-through apparatus setup was described previously [23]. Briefly, AmB release studies were carried out in a flow-through dissolution apparatus (Sotax CE7 smart connected to a Sotax piston pump CP7, Sotax, Aesch Switzerland) operated in the closed mode [26]. A $5 \mathrm{~mm}$ ruby glass bead was positioned at the bottom of the cell (large cell: $22.6 \mathrm{~mm}$ diameter). The dialysis membrane was placed into the flow through cell apparatus dialysis adapter and Ambisome ${ }^{\circledR}$ powder $(0.5 \mathrm{mg} \mathrm{AmB})$ was placed into the membrane with $1 \mathrm{~mL}$ of the release medium. Glass fibre filters (GF/D, GF/F) were positioned at the top of the cell. The release studies were based on a two level factorial DoE, where the velocities used were considered biorelevant: "Low velocity" (flow rate: $8 \mathrm{~mL} / \mathrm{min}$ ) has an average linear velocity comparable to capillary flow and "High velocity" (flow rate: $35 \mathrm{~mL} / \mathrm{min}$ ) is comparable to intermediate capillary-vein flow [23] and BSA presence (4.0\% w/v) or not were the factors investigated. $36 \mathrm{~mL}$ of KRB BS $20.0 \mathrm{mM}$ PL 4.0 mM (with or without BSA) were used in order to simulate the equivalent volume available on administration of $1 \mathrm{mg} / \mathrm{kg}$ of $\mathrm{AmB}$ as $\mathrm{Amphotericin} \mathrm{B}^{\circledR}$ to a $70 \mathrm{~kg}$ subject (assuming $5 \mathrm{~L}$ of blood volume). Furthermore, as the $36 \mathrm{~mL}$ volume used does not allow for distribution as would happen in vivo, it represents an extreme case in terms of available volume.

\subsection{Release data treatment}

The release data treatment was described previously [23]. Briefly, for the studies with the sample and separate method, \% AmB released over time was calculated based on the $\%$ AmB still entrapped in the liposomes at the time of sampling (\%AmB $\left.B_{\text {liposomal }}\right)(\mathrm{Eq} 1)$ to construct 
the calculated $\% A m B_{\text {released }}$ profile. $\% A m B_{\text {released }}=\% A m B_{\text {initial }}-\% A m B_{\text {liposomal }}$

\section{(Eq 1)}

where $\% A m B_{\text {initial }}$ is the mass of $\mathrm{AmB}$ placed into the reservoir initially (100\%) and $\% A m B_{\text {released }}$ is the calculated $\mathrm{AmB}$ percent released.

For the studies with the continuous flow setup the $\% A m B_{\text {released }_{(o b s)}}$ over time was corrected for degradation using Eq 2 to construct the calculated $\% A m B_{\text {released }}$ profile.

$\% A m B_{\text {released }}=\% A m B_{\text {released }_{(o b s)}}+k_{\text {deg }} * A U C_{0-t}$

where $\% A m B_{\text {released }}$ is the corrected $\% \mathrm{AmB}$ released accounting for degradation, $\% A m B_{\text {released }_{(o b s)}}$ is the $\% \mathrm{AmB}$ released at time $t, A U C_{0-t}$ is the Area Under the Curve of the observed concentration - time curve from time 0 to time $t$ and $k_{\text {deg }}$ is the degradation rate constant obtained from the degradation experiments [22].

The AmB release rate constant $\left(k_{r e l}\right)$ from Ambisome ${ }^{\circledR}$ was obtained from first order fitting of calculated $\% A m B_{\text {released }}$ individual profiles (Equation 3) and mean and standard deviation values were calculated (GraphPad Prism 7, GraphPad Software, Inc, USA).

$\% A m B_{\text {released }}=\% A m B_{\text {released }} \max *\left(1-e^{-k_{\text {rel }} t}\right)($ Equation 3$)$,

where $\% A m B_{\text {released }}$ max is the maximum $\mathrm{AmB}$ percent released and $t$ is time.

\subsection{Atomic Force Microscopy (AFM) studies}

To further investigate the effect of the clinically relevant media components (e.g. BS, PL and BSA) on the liposomes, AFM studies were performed. The AFM methodology has been described previously [23]. Ambisome ${ }^{\circledR}$ liposomes were incubated in KRB BS 20.0 mM PL 4.0 $\mathrm{mM}$ BSA $4.0 \% \mathrm{w} / \mathrm{v}$ (for $30 \mathrm{~min}$ ) and in KRB BS 20.0mM PL $4.0 \mathrm{mM}$ (for $5 \mathrm{~min}$; a shorter period of incubation was set in order to reflect the fast release of $\mathrm{AmB}$ from the liposomes 
observed in the absence of BSA). After the incubation time, samples were centrifuged for 30 min at 13,300 rpm in an Eppendorf centrifuge, the supernatant was discarded and the pellet was dried under vacuum. The pellets were diluted with $1 \mathrm{~mL}$ of HPLC water, and then $10 \mu \mathrm{L}$ of the liposomal solution was placed on a freshly cleaved mica surface $(1.5 \mathrm{~cm} \times 1.5 \mathrm{~cm}$; $\mathrm{G} 250$ 2 Mica sheets 1" $\times 1 " \times 0.006^{\prime \prime}$; Agar Scientific Ltd., Essex, UK). The sample was then airdried for $\sim 30$ min and imaged immediately by scanning the mica surface in air under ambient conditions using a Bruker MultiMode 8 Scanning Probe Microscope (Bruker, Billerica, Massachusetts, USA) operated on Peak Force QNM mode. The AFM measurements were obtained using ScanAsyst-air probes (Bruker, Billerica, Massachusetts, US); the spring constant was calibrated by thermal tune (Nominal $0.4 \mathrm{~N} \mathrm{~m}^{-1}$ ) and the deflection sensitivity calibrated using a silica wafer. AFM scans were acquired at a resolution of $512 \times 512$ pixels at scan rate of $1 \mathrm{~Hz}$, and produced topographic images of the samples in which the brightness of features increases as a function of height. The raw image data were processed using Bruker Nanoscope Analysis (version 1.5), and height images were flattened to remove sample tilt and scanner bow. The surface roughness $\left(\mathrm{R}_{\mathrm{a}}\right)$ of each substrate was determined by using Nanoscope Analysis' algorithm to analyse several scans of the surface from different locations $(n=20)$. AFM images were collected from random spot surface sampling (at least four areas).

\subsection{PBPK modeling for Ambisome ${ }^{\circledR}$ administration to healthy subjects}

\subsubsection{Data for PBPK modeling.}

Published data of plasma concentration profiles from a population of 5 healthy subjects (4 males, 1 female; ages from 33 to 65 years; height from 1.61 to $1.68 \mathrm{~m}$; and weight from 68 to $86 \mathrm{~kg}$ ) administered $2.0 \mathrm{mg} / \mathrm{kg}$ of Ambisome ${ }^{\circledR}$ by intravenous infusion over $2 \mathrm{~h}$ where the "liposomal AmB" and "released AmB" were quantified [27, 28], were digitalized with Webplot 
234

digitalizer 3.8 software. "Liposomal AmB" and "released AmB" distribution, clearance, protein 235 binding and physicochemical properties are shown in Table 2.

236 The PK parameters (distribution, clearance and protein binding) for "released AmB" were as 237 reported by Kagan et al. after administration of the colloidal AmB formulation Fungizone ${ }^{\circledR}$ 238 [21] (Table 2). Protein binding was characterized by $\mathrm{k}_{\text {diss }}$ (equilibrium dissociation constant). 239 The nominal glomerular filtration rate (GFR) for AmB was $0.08 \mathrm{~mL} / \mathrm{min} / \mathrm{kg}$ as calculated using $240 \mathrm{Eq} 4$, based on a fraction unbound of 0.05 . This value was used to calculate the GFR fraction 241 for the "liposomal AmB" and "released AmB".

242 Nomimal GFR = fraction unbound $($ albumin $) *(120 \mathrm{~mL} / \mathrm{min}) *(1 / 73 \mathrm{~kg}) \quad \mathrm{Eq}$ 2434

244 The biliary elimination rate constant was calculated using Eq 5.

$245 k_{\text {bil }}=\left(C l_{\text {biliary }} /\right.$ distributuion volume $)(60 \mathrm{~min} / 1 \mathrm{~h}) \mathrm{Eq} 5$.

246 For the development of the model, "liposomal AmB" was assumed to behave as a molecule as 247 the concentration of $\mathrm{AmB}$ is what is quantified in the in vivo studies and not the concentration 248 or amount of liposomes.

249 An "immune" enzyme was added for the "liposomal AmB" to account for the removal of 250 circulation of the "liposomal AmB" by the macrophages of the immune system. The enzyme 251 was set to be located in the plasma, liver and spleen. The fraction unbound value for the 252 "liposomal AmB" was hypothesized to be smaller than 0.95 based on the reported interaction 253 between albumin and liposomes [38-40]. All the other parameters were left as software default 254 values.

255 2.7.2. Workflow for PBPK modeling of Ambisome ${ }^{\circledR}$ 
The workflow for the PBPK modeling to describe the pharmacokinetics of "liposomal AmB" and "released AmB" in a healthy individual after the administration of the Ambisome ${ }^{\circledR}$ is presented in Figure 1.

PBPK modeling was performed with PKSim ${ }^{\circledR} 7.2 .1$ (Bayer, Germany) and MoBi ${ }^{\circledR} 7.2$ (Bayer, Germany). The five parameters listed in Figure 1 were optimized simultaneously with the $\mathrm{MoBi}^{\circledR}$ built in function "Parameter identification" using an algorithm based on Monte Carlo methods and the default software setup (the Parameter identification tool varies selected input parameters in a given range to identify the best values to obtain output simulated curves similar to the observed curves). The in vivo release of $\mathrm{AmB}$ from the liposomes was set to occur only in plasma $\left(k_{r e l-i v}\right)$.

Comparing the developed PBPK model in this study with that reported by Kagan et al [21], there were some differences: i) this model was developed in order to link the in vitro release data to the observed plasma concentration data while Kagan and co-workers developed their model to have a better understanding of AmB PK in order to improve dosing; ii) the model developed by Kagan et al. assumed that release of AmB took place in all compartments [21] while in this study, the release was modelled in plasma only.

Sensitivity analysis was performed on all the parameters of the model (PK parameter estimates and physicochemical properties of "liposomal AmB" and "released AmB") except for the molecular weight and the pKa values of "released AmB". The parameters and the range in which the sensitivity analysis was evaluated are presented in Table 3.

The ranges were selected as follows: $\log \mathrm{P}$ of "liposomal AmB" and "released AmB": $\pm 1 \log$ unit of the optimized value, immune enzyme of "liposomal AmB": $\pm 1 \mathrm{~h}^{-1}$ of the optimized value, aqueous solubility of "released AmB": the range was selected to cover the solubility values reported in the literature [33-35], aqueous solubility of "liposomal AmB": $\pm 200 \mu \mathrm{g} / \mathrm{mL}$ 
in order to cover a wide range as the solubility value was calculated by considering the total amount of formulation powder in a vial (14.5 g), dissolved in $50 \mathrm{~mL}$ of water (Table 2); for radius solute ("liposomal AmB"), biliary clearance ("liposomal AmB" and "released AmB"), $k_{\text {diss }}$ of lipoprotein B (APOB) and alpha1-acid glycoprotein (AAG1) the interval was $\pm 50 \%$ of the literature value (Table 2 and 3). The GFR fraction ("liposomal AmB" and "released AmB") was investigated ranging from 0 to 1 ; and the unbound to protein fraction ("liposomal $A m B "$ and "released AmB") from 0.05 to $0.95 . k_{r e l-i v}$ was investigated in the interval of the $k_{r e l}$ found in the in vitro tests (Table 3 ). $A U C_{0-24 h}$ of both liposomal and released AmB was used as response to evaluate the effect of the parameters investigated. Sensitivity analysis was performed with the MoBi Toolbox for R esqLABS version 7.2.1 (esq LABS, Germany). All the intervals tested, were normalized to $0-1$ for clarity of presentation.

After the sensitivity analysis, the model was applied to the population described in section 2.7.1. The variability (standard deviation) for the parameters input into the model was as described in Table 2. As the values of $k_{r e l-i v}$ and specific clearance for the immune removal "enzyme" were obtained by parameter identification and there are no reported values for their variability, $20 \%$ of the identified value was used as standard deviation.

\subsubsection{Evaluation of the in vitro tests using PBPK modeling}

The in vitro $k_{\text {rel }}$ (Mean $\pm \mathrm{SD}$ ) obtained from the in vitro release profiles of AmB from Ambisome ${ }^{\circledR}$ were input to the validated PBPK model in order to predict the observed in vivo $\mathrm{AmB}$ ("liposomal AmB" and "released $\mathrm{AmB}$ ") plasma concentration profiles. The $A U C_{0-24 h}$ was calculated from the predicted "liposomal AmB" and "released AmB" plasma concentration profiles.

\subsection{PBPK-PD model for the pharmacological activity of AmB against Candida albicans}


The effect of AmB on Candida albicans (C. albicans) was investigated in order to develop a PBPK-PD model: i. for a patient population receiving Ambisome ${ }^{\circledR}$ with a reduced albumin plasma concentration (hypalbuminaemia: albumin $<25 \mathrm{mg} / \mathrm{mL}$ ), and ii. for a healthy population receiving Ambisome ${ }^{\circledR}$ with normal concentration of albumin $(\sim 4.0 \% \mathrm{w} / \mathrm{v})$.

\subsubsection{Quantification of $C$. albicans}

The culture and quantification of $C$. albicans was described previously [25]. A single colony culture was started in a tube with $5 \mathrm{~mL}$ of SBD broth and incubated overnight at $37^{\circ} \mathrm{C}$ in a shaking incubator; the optical density was measured at $600 \mathrm{~nm}\left(\mathrm{OD}_{600}\right)$. The colony forming units (CFU) were determined by preparing serial dilutions and the suspensions were plated on SBD agar plates, incubated overnight at $37^{\circ} \mathrm{C}$ and the number of colonies were counted and related to the $\mathrm{OD}_{600}$ of the culture.

\subsubsection{Time killing experiments}

Time killing experiments were performed with $10^{5} \mathrm{CFU} / \mathrm{mL}$ of $C$. albicans using different AmB final concentrations $(0.00,0.75,1.50$ and $3.00 \mu \mathrm{g} / \mathrm{mL})$ in the presence of BSA $2.0 \%$ and $4.0 \% \mathrm{w} / \mathrm{v}$ in $\mathrm{KRB}$ [an experiment without $\mathrm{AmB}$ was performed in order to obtain the $k_{\text {growth }}$ of the fungal cells]. The \% CFUs remaining at each time point were used for curve fitting to the exponential decay equation to obtain the killing rate coefficient for each concentration tested (Eq 6).

$\% C F U=\% C F U_{\text {max }} * e^{-k_{\text {kill }} t}$ Eq 6.

where $\% C F U$ is the $\% C F U$ at time t, $\% C F U_{\max }$ is the maximum $\% C F U, k_{\text {kill }}$ is the time killing rate coefficient and $t$ is time.

A linear relation was found between $k_{\text {kill }}$ and $\mathrm{AmB}$ concentration and it was used in the PBPKPD model. 


\subsubsection{PBPK-PD modeling}

The workflow for the development of the PBPK-PD model is shown in Figure 2.

To simulate a hypoalbuminaemic patient population, the protein content was halved in the validated PBPK model for the healthy subjects and the rest of the parameters remained unchanged. The "released AmB" concentration was used to calculate the $k_{k i l l}$ for the $24 \mathrm{~h}$ time course to simulate the "released AmB" activity against $C$. albicans which was set at a concentration of $10^{5} \mathrm{CFU} / \mathrm{mL}$ at time zero. The $C$. albicans growth rate constant $\left(k_{\text {growth }}\right)$ was obtained from the control time killing experiment $(0.00 \mu \mathrm{g} / \mathrm{mL} \mathrm{AmB})$ by fitting the data to an exponential growth equation (Eq 7)

$\% C F U=A e^{k_{\text {growtht }}}(\mathrm{Eq} 7)$

where $\% C F U$ is the $\% C F U$ at time $\mathrm{t}, A$ is the starting $\mathrm{CFU}$ value, $k_{\text {growth }}$ is the growth rate constant and $t$ is time.

\subsection{Statistical analysis}

The statistical analysis was described previously [23]. Pareto charts, based on the DoE analysis, were performed for the identification of significant effects from the in vitro release tests. A factor was significant when the standardized effect (bars) was larger than the line for statistical significance level $(\alpha=0.05)$ (vertical line). An independent means $t$ - test was performed to compare 2 independent means: in the AFM studies, size and surface roughness were compared against the control sample. A p $<0.05$ was considered statistically significant. Due to the lack of individual observed data of plasma concentration profiles, the in vitro $k_{r e l}$ were input into the PBPK model to obtain simulated $A U C_{0-24 h}$ which were compared against the $A U C_{0-24 h}$

347 obtained from the simulated data generated by the validated PBPK model. 
Additionally, the $90 \%$ confidence interval $(90 \% \mathrm{CI})$ for the ratio of the geometric means of the simulated $A U C_{0-24 h}$ obtained with the in vitro $k_{\text {rel }}$ and the $A U C_{0-24 h}$ obtained from the simulated data generated by the validated PBPK model were calculated. As recommended by the FDA guidance, both "liposomal AmB" and "released AmB" were evaluated [39]. Data analysis, creation and analysis of DoE were performed with the statistical software Statgraphics Centurion XVII (USA) and the 90\% CI were calculated with IBM SPSS Statistics 25 (USA).

\section{Results and discussion}

\subsection{In vitro release testing of Ambisome ${ }^{\circledR}$}

In vitro release profiles of $\mathrm{AmB}$ from Ambisome ${ }^{\circledR}$ in both hydrodynamic setups are shown in Figure 3 and parameters obtained after fitting to the first order equation model are presented in Table 4.

For the sample and separate setup, the statistical analysis (Figure 4a) showed that the buffer was a significant factor affecting $\% A m B_{\text {released }} \max$ with a higher release in $\mathrm{KRB}$, the presence of BSA $4.0 \% \mathrm{w} / \mathrm{v}$ had a significant negative effect. The interaction between buffer and BSA was significant as the amount released in KRB with BSA is slightly higher than in PBS with BSA, while in media without BSA there is no difference. The release rate constant was affected in the same way as $\% A m B_{\text {released }}$ max but the interaction between buffer and BSA showed that the release rate is faster in KRB than in PBS without BSA and there is not a statistical significant difference in KRB and PBS with BSA. For the continuous flow setup (Figure $4 \mathrm{~b}$ ), the flow rate was the only significant factor affecting AmB release from the liposomes, with a positive effect on the $A U C_{0-12 h}$.

\subsection{AFM studies}


Figure 5 shows the images obtained from the AFM and Table 5 contains the parameters of the liposome characteristics measured by AFM.

Diameter of the liposomal structures in samples from KRB BS $20.0 \mathrm{mM}$ PL $4.0 \mathrm{mM}$ are significantly higher than the control sample; liposomes could be merging with each other or the inclusion of BS PL could alter the structure of the liposome resulting in a higher size before the disruption. Liposomes were not visible in the sample of from KRB BS $20.0 \mathrm{mM}$ PL 4.0 $\mathrm{mM} \mathrm{BSA} 4.0 \% \mathrm{w} / \mathrm{v}$, probably due to the incubation period of this sample.

\subsection{PBPK modeling of Ambisome ${ }^{\circledR}$ administered to healthy subjects}

The simulated plasma concentration profiles obtained with the validated PBPK model for the administration of Ambisome ${ }^{\circledR}$ to healthy subjects are shown in Figure 6.

Using the parameter identification method, the optimal values for the parameters investigated were: $k_{\text {rel-iv }}=0.60 \mathrm{~h}^{-1}, \log \mathrm{P}($ released $\mathrm{AmB})=3.24, \log \mathrm{P}($ liposomal $\mathrm{AmB})=1.0$, Specific clearance for the immune removal "enzyme" $=2.57 \mathrm{~h}^{-1}$ and AAG1 $k_{\text {diss }}=0.42 \mu \mathrm{mol} / \mathrm{L}$. The $\log \mathrm{P}$ and clogP values reported in the literature, are between -2.33 to 2.14 (Table 2) providing a wide interval for the true value. The value obtained from parameter identification fitting was 3.24 which could be supported considering the distribution of the values previously reported (Table 2).

The PBPK model described closely the average observed data for "liposomal AmB" and "released $\mathrm{AmB} "\left(\% . A U C_{0-24 h}\right.$ predicted $/ A U C_{0-24 h}$ observed were $94 \%$ and $101 \%$, respectively). Comparing the developed PBPK model in this study with the one reported by Kagan et al [21], the main difference was the $k_{r e l-i v}$ from this model was faster: $0.60 \mathrm{~h}^{-1}>$ $0.0035 \mathrm{~h}^{-1}[21]$ and there was no initial rapid release of $8.0 \%$ of the dose, as was included by Kagan et al [21]. It could be due to simulated $\mathrm{AmB}$ release taking place in all of the 
compartments in the model presented by Kagan et al. [21], while in this study; the release was only in plasma.

The sensitivity analysis is shown in Figure 7. Parameters such as aqueous solubility ("liposomal $A m B "$ and "released AmB"), solute radius ("liposomal AmB"), specific biliary clearance ("liposomal AmB" and "released AmB"), $k_{\text {diss }}$ for AAG1 and APOB ("released AmB"), and the GFR for "released AmB" did not have a significant impact on the $A U C_{0-24 h}$ of "liposomal AmB" or "released AmB". For the "liposomal AmB", the fraction unbound to proteins had the greatest impact on the model. It can be observed how the "liposomal AmB" in plasma decreases as the fraction unbound increases, leading to a decrease in "released AmB", as there will be less "liposomal AmB" available in plasma to release drug. $k_{r e l-i v}$ had a high impact on both "liposomal AmB" and "released AmB" (Figure 7), with a higher release rate constant leading to an increase in the "released $\mathrm{AmB}$ " and a decrease in the "liposomal AmB". For "released $\mathrm{AmB} ", \log \mathrm{P}$ is the factor with the highest effect on $A U C_{0-24 h}$.

\subsection{Evaluation of the in vitro release profiles using the PBPK model}

The predictability of the in vitro release tests is presented in Figure 8 for both "liposomal AmB" and "released AmB".

For the "liposomal AmB", the $A U C_{0-24 h}$ obtained with the in vitro $k_{r e l}$ where BSA was present in the media were similar to the $A U C_{0-24 h}$ obtained from the validated PBPK model, regardless of the type of the buffer or the hydrodynamic conditions. The $A U C_{0-24 h}$ values were only similar for a medium without BSA in the low velocity setup (Figure 8). For the "released AmB", the $A U C_{0-24 h}$ obtained with the in vitro $k_{r e l}$ in media with BSA were close to attaining similarity to the in vivo profiles, as all the tests (except KRB BS PL BSA low agitation) revealed one extreme of the $90 \%$ CI between $80-125 \%$. It can be noticed that the tests performed with the continuous flow setup under-predicted the plasma concentration of the 
"released AmB". An increasing flow rate leads to a higher drug release (Figure 4) thus further exploration of flow rate effect could be conducted to identify the flow rate resulting in release profiles suitable for simulation of in vivo release. The $A U C_{0-24 h}$ could not be calculated for the high velocity profiles as for the medium without BSA the standard deviation was higher than the mean and for the medium with BSA the profiles could not be fitted to the first order equation. The model developed is suitable for the evaluation of the in vitro release tests and could support the development of a biopredictive in vitro release test. It has to be noted that for the prediction of the plasma concentration of "liposomal AmB" and "released AmB", the presence of BSA was a critical factor, thus, information on the exact mechanism of the protein binding to the liposomes could further improve the model developed. Furthermore, the accuracy of model could be further improved through inclusion of parameters capturing AmB binding to red blood cells, as in general only plasma concentrations are presented in the literature while the formulation is obviously administered to the venous blood pool.

\subsection{PBPK - PD modeling for the patient (hypoalbuminaemic) population.}

Parameters obtained after fitting to the exponential decay equation model for the time killing experiments are presented in Table 6. A linear relationship between the AmB concentration and the time killing rate coefficient was found for experiments with BSA 2.0 and $4.0 \% \mathrm{w} / \mathrm{v}$, (Eq 8 and eq. 9, respectively)

time killing rate coefficient $\left(h^{-1}\right)=0.1923\left(m L * h^{-1}\right) / \mu g+0.2102 h^{-1}$ Eq 8 .

time killing rate coefficient $\left(h^{-1}\right)=0.1167\left(m L * h^{-1}\right) / \mu g+0.014 h^{-1} \quad$ Eq 9.

The simulated plasma concentration profiles for "liposomal AmB" and "released AmB" in the extrapolated hypoalbuminaemic population and the healthy subject population are presented in Figure 9a. It can be observed that both "liposomal AmB" and "released AmB" are at a lower concentration as a consequence of the decrease of the amount of proteins present. There is a 
lower concentration as with more unbound drug there is more drug available for distribution and clearance. Figure $9 \mathrm{~b}$ shows the simulated plasma concentration profiles for a typical administration of Ambisome ${ }^{\circledR}$ to a patient with a systemic fungal infection (300 mg, infusion $4 \mathrm{~h}$ ) in the simulated hypoalbumanaemic patient and in a subject with normal albumin levels.

Equations 8 and 9 were used in the PBPK-PD model to simulate the killing of $C$. albicans (Figure 9c).It can be observed how the growth of the fungal cells is reduced by the administration of Ambisome $^{\circledR}$ (Figure 9d) with a higher effect in the simulated hypoalbuminaemic patient than in the subject with normal albumin levels. From the time killing studies and previous data on minimum inhibitory and fungicidal concentrations [25], a higher fungicidal effect is reached with a lower AmB concentration in the presence of BSA $2.0 \% \mathrm{w} / \mathrm{v}$ as there is more unbound drug able to exert its pharmacological effect. It has to be noted that only the effect of released AmB is evaluated in this PBPK-PD model. The humoral and cellular immune responses and the effect that the liposomal AmB could have on $C$. albicans are not considered, nor is the effect of fungal phospholipases on liposomal integrity and $\mathrm{AmB}$ release. A number of $10^{5} \mathrm{CFU} / \mathrm{mL}$ were used to simulate the effect of $\mathrm{AmB}$ in vivo as this was the concentration of the fungal cell suspensions used in the time killing experiments. It has been reported that a concentration of $100-1000 \mathrm{CFU} / \mathrm{mL}$ are found in cultures of blood from patients with systemic fungal infection [41, 42]. The PBPK-PD analysis could be further improved by using the adequate number of $\mathrm{CFU}$ quantified in plasma from infected patients to evaluate the response of the humoral immune response and not only the effect of the protein content. In plasma from healthy subjects the fungal cells did not grow (data not shown), thus, the results of the PBPK-PD model for the healthy subject must be only considered as an exercise for comparative purposes. For this model, only the changes in the albumin levels were considered, leaving aside the physiological characteristics of septic or critically ill patients. In order to improve the model, the change in the activity of the immune enzyme should be 
adjusted to the patient population as the immune system might be compromised or activated, and the $k_{r e l-i v}$, which the in vitro tests showed to be dependent on the albumin concentration, should also be adjusted. This approach reveals the potential of the use of in vitro release data and suitable microbiology data in combination with a PBPK-PD model in order to guide parenteral formulation development based on pharmacodynamics and therapeutic outcomes.

\section{Conclusions}

The literature available for in vitro release testing of controlled release parenteral formulations is limited. The evaluation of factors that can affect the release from these formulations and the development of in vitro release tests that are able to predict the in vivo performance are of high importance. In this work, the development of a clinically relevant in vitro release test for the liposomal formulation of AmB (Ambisome ${ }^{\circledR}$ ) was investigated. A PBPK model was developed for the administration of Ambisome ${ }^{\circledR}$ to healthy subjects, which was used to identify the critical factors for AmB release from liposomes and the in vivo predictability of the in vitro release tests. The presence of BSA in the media was the most critical factor affecting the AmB release, and the in vitro release profiles from tests with BSA in the medium were biopredictive.

Successful predictions of the "liposomal AmB" and the "released AmB" plasma concentration profile were obtained with both hydrodynamic setups tested (sample and separate method and continuous flow method). A PBPK-PD model of the activity of AmB on fungal cells was developed based on the predicted "released AmB" plasma concentration profile in a hypoalbuminaemic population in order to illustrate the potential of linking in vitro release testing, PBPK modeling and microbiology data.

\section{Acknowledgments}


489 Part of this work has been previously presented at the AAPS PharmSci 360 annual meeting in

490 Washington, DC November 2018 (poster presentation). The authors would like to thank the 491 Mexican Council of Science and Technology (CONACyT) for the PhD scholarship of Dr R 492 Diaz de Leon-Ortega, Dr Wei-Feng Xue (University of Kent, UK) for his help with the AFM 493 studies, Dr Albert Bolhuis for his help with the microbiology studies and Dr Andrea Edginton 494 (University of Waterloo, Canada) for her help with PK-Sim ${ }^{\circledR}$ software. 


\section{References}

[1] A. Abend, T. Heimbach, M. Cohen, F. Kesisoglou, X. Pepin, S. Suarez-Sharp, Dissolution and Translational Modeling Strategies Enabling Patient-Centric Drug Product Development: the M-CERSI Workshop Summary Report, The AAPS Journal, 20 (2018) 60.

[2] P. Espié, D. Tytgat, M.-L. Sargentini-Maier, I. Poggesi, J.-B. Watelet, Physiologically based pharmacokinetics (PBPK), Drug Metabolism Reviews, 41 (2009) 391-407.

[3] F. Khalil, S. Laer, Physiologically based pharmacokinetic modeling: methodology, applications, and limitations with a focus on its role in pediatric drug development, Journal of biomedicine \& biotechnology, 2011 (2011) 907461.

[4] H.M. Jones, I.B. Gardner, K.J. Watson, Modelling and PBPK Simulation in Drug Discovery, The AAPS Journal, 11 (2009) 155-166.

[5] H.K. Batchelor, N. Fotaki, S. Klein, Paediatric oral biopharmaceutics: key considerations and current challenges, Advanced drug delivery reviews, 73 (2014) 102-126.

[6] F. Kesisoglou, J. Chung, J. van Asperen, T. Heimbach, Physiologically Based Absorption Modeling to Impact Biopharmaceutics and Formulation Strategies in Drug DevelopmentIndustry Case Studies, Journal of pharmaceutical sciences, 105 (2016) 2723-2734.

[7] X. Zhuang, C. Lu, PBPK modeling and simulation in drug research and development, Acta Pharmaceutica Sinica B, 6 (2016) 430-440.

[8] FDA, 2018. Physiologically Based Pharmacokinetic Analyses — Format and Content.

Available from:

https://www.fda.gov/downloads/Drugs/GuidanceComplianceRegulatoryInformation/Guidanc es/UCM531207.pdf. Access date: 31/07/2019.

[9] EMA, Guideline on the qualification and reporting of physiologically based pharmacokinetic (PBPK) modelling and simulation, 2016. Available from: https://www.ema.europa.eu/documents/scientific-guideline/guideline-qualification-reporting- 
physiologically-based-pharmacokinetic-pbpk-modelling-simulation_en.pdf. Access date:

$31 / 07 / 2019$

[10] X.Y. Zhang, M.N. Trame, L.J. Lesko, S. Schmidt, Sobol Sensitivity Analysis: A Tool to

Guide the Development and Evaluation of Systems Pharmacology Models, CPT: pharmacometrics \& systems pharmacology, 4 (2015) 69-79.

[11] K. McNally, R. Cotton, G.D. Loizou, A Workflow for Global Sensitivity Analysis of PBPK Models, Frontiers in pharmacology, 2 (2011) 31.

[12] M. Ulldemolins, J.A. Roberts, J. Rello, D.L. Paterson, J. Lipman, The effects of hypoalbuminaemia on optimizing antibacterial dosing in critically ill patients, Clinical Pharmacokinetics, 50 (2011) 99-110.

[13] L. Kuepfer, C. Niederalt, T. Wendl, J.F. Schlender, S. Willmann, J. Lippert, M. Block, T. Eissing, D. Teutonico, Applied Concepts in PBPK Modeling: How to Build a PBPK/PD Model, CPT: pharmacometrics \& systems pharmacology, 5 (2016) 516-531.

[14] K. Chen, S. Teo, K.Y. Seng, Sensitivity analysis on a physiologically-based pharmacokinetic and pharmacodynamic model for diisopropylfluorophosphate-induced toxicity in mice and rats, Toxicology mechanisms and methods, 19 (2009) 486-497.

[15] E. Asin-Prieto, A. Rodriguez-Gascon, A. Isla, Applications of the pharmacokinetic/pharmacodynamic (PK/PD) analysis of antimicrobial agents, Journal of infection and chemotherapy : official journal of the Japan Society of Chemotherapy, 21 (2015) 319-329.

[16] E.I. Nielsen, O. Cars, L.E. Friberg, Pharmacokinetic/pharmacodynamic (PK/PD) indices of antibiotics predicted by a semimechanistic PKPD model: a step toward model-based dose optimization, Antimicrobial agents and chemotherapy, 55 (2011) 4619-4630.

[17] M.W. Sadiq, E.I. Nielsen, D. Khachman, J.M. Conil, B. Georges, G. Houin, C.M. Laffont, M.O. Karlsson, L.E. Friberg, A whole-body physiologically based pharmacokinetic (WB- 
PBPK) model of ciprofloxacin: a step towards predicting bacterial killing at sites of infection,

Journal of pharmacokinetics and pharmacodynamics, 44 (2017) 69-79.

[18] J. Mora-Duarte, R. Betts, C. Rotstein, A.L. Colombo, L. Thompson-Moya, J. Smietana,

R. Lupinacci, C. Sable, N. Kartsonis, J. Perfect, Comparison of caspofungin and amphotericin B for invasive candidiasis, The New England journal of medicine, 347 (2002) 2020-2029.

[19] E.M. Johnson, J.O. Ojwang, A. Szekely, T.L. Wallace, D.W. Warnock, Comparison of In Vitro Antifungal Activities of Free and Liposome-Encapsulated Nystatin with Those of Four Amphotericin B Formulations, Antimicrob. Agents. Chemother., 42 (1998) 1412-1416.

[20] L. Kagan, P. Gershkovich, K.M. Wasan, D.E. Mager, Physiologically Based Pharmacokinetic Model of Amphotericin B Disposition in Rats Following Administration of Deoxycholate Formulation (Fungizone ${ }^{\circledR)}$ : Pooled Analysis of Published Data, The AAPS Journal, 13 (2011) 255.

[21] L. Kagan, P. Gershkovich, K.M. Wasan, D.E. Mager, Dual Physiologically Based Pharmacokinetic Model of Liposomal and Nonliposomal Amphotericin B Disposition, Pharmaceutical Research, 31 (2014) 35-45.

[22] R. Díaz de León-Ortega, D.M. D'Arcy, N. Fotaki, Investigating Factors That Affect In vitro Drug Release From A Parenteral Liposomal Formulation, in: AAPS, Washington DC, USA, 2018.

[23] R. Diaz de Leon-Ortega, D.M. D'Arcy, D.L. Lamprou, W.F. Xue, N. Fotaki, In vitro in vivo relations for the parenteral liposomal formulation of Amphotericin B. Part 1: A biorelevant and clinically relevant approach, Submitted to the Journal of Controlled Release, (2019).

[24] P. Egger, R. Bellmann, C.J. Wiedermann, Determination of amphotericin B, liposomal amphotericin B, and amphotericin B colloidal dispersion in plasma by high-performance liquid chromatography, J. Chromatogr. B: Anal. Technol. Biomed. Life Sci., 760 (2001) 307-313. 
571 [25] R. Diaz de Leon-Ortega, D.M. D'Arcy, A. Bolhuis, N. Fotaki, Investigation and simulation

572 of dissolution with concurrent degradation under healthy and hypoalbuminaemic simulated

573 parenteral conditions- case example Amphotericin B, European journal of pharmaceutics and 574 biopharmaceutics : official journal of Arbeitsgemeinschaft fur Pharmazeutische 575 Verfahrenstechnik e.V, (2018).

576 [26] N. Fotaki, Flow-through cell apparatus (USP apparatus 4): Operation and features, 577 Dissolution Technol, 18 (2011) 46-49.

578 [27] I. Bekersky, R.M. Fielding, D.E. Dressler, J.W. Lee, D.N. Buell, T.J. Walsh, 579 Pharmacokinetics, Excretion, and Mass Balance of Liposomal Amphotericin B (AmBisome) 580 and Amphotericin B Deoxycholate in Humans, Antimicrobial Agents and Chemotherapy, 46 $581 \quad(2002) 828-833$.

582 [28] I. Bekersky, R.M. Fielding, D.E. Dressler, J.W. Lee, D.N. Buell, T.J. Walsh, Plasma 583 protein binding of amphotericin B and pharmacokinetics of bound versus unbound 584 amphotericin B after administration of intravenous liposomal amphotericin B (AmBisome) and 585 amphotericin B deoxycholate, Antimicrob. Agents. Chemother., 46 (2002) 834-840.

586 [29] DrugBank, Amphotericin B, 2005. Available from: 587 https://www.drugbank.ca/drugs/DB00681. Access date: 31/07/2019

588 [30] Sigma-Aldrich, Amphotericin B, 2015. Available from: 589 https://www.sigmaaldrich.com/content/dam/sigma-

590 aldrich/docs/Sigma/Datasheet/6/a9528dat.pdf. Access date: 31/07/2019

591 [31] S.S. Bharate, V. Kumar, R.A. Vishwakarma, Determining Partition Coefficient (Log P), 592 Distribution Coefficient (Log D) and Ionization Constant (pKa) in Early Drug Discovery, 593 Combinatorial chemistry \& high throughput screening, 19 (2016) 461-469.

594 [32] ChemSpider, Amphotericin B, 2015. Available from: 595 http://www.chemspider.com/Chemical-Structure.10237579.html. Access date: 31/07/2019 
[33] M.T. Lamy-Freund, V.F. Ferreira, S. Schreier, Polydispersity of aggregates formed by the polyene antibiotic amphotericin B and deoxycholate. A spin label study, Biochim. Biophys. Acta, Biomembr., 981 (1989) 207-212.

[34] J. Mazerski, J. Grzybowska, E. Borowski, Influence of net charge on the aggregation and solubility behaviour of amphotericin B and its derivatives in aqueous media, European biophysics journal, 18 (1990) 159-164.

[35] J. Barwicz, S. Christian, I. Gruda, Effects of the aggregation state of amphotericin B on its toxicity to mice, Antimicrob. Agents. Chemother., 36 (1992) 2310-2315.

[36] Y. Ridente, J. Aubard, J. Bolard, Absence in amphotericin B-spiked human plasma of the free monomeric drug, as detected by SERS, FEBS letters, 446 (1999) 283-286.

[37] Gilead, Ambisome®,

http://www.gilead.com/ /media/files/pdfs/medicines/other/ambisome/ambisome_pi.pdf?la=e n, (2015).

[38] Y. Yokouchi, T. Tsunoda, T. Imura, H. Yamauchi, S. Yokoyama, H. Sakai, M. Abe, Effect of adsorption of bovine serum albumin on liposomal membrane characteristics, Colloids and Surfaces B: Biointerfaces, 20 (2001) 95-103.

[39] T. Hernández-Caselles, J. Villalaín, J.C. Gómez-Fernández, Influence of liposome charge and composition on their interaction with human blood serum proteins, Molecular and Cellular Biochemistry, 120 (1993) 119-126.

[40] S.L. Law, W.Y. Lo, S.H. Pai, G.W. Teh, F.Y. Kou, The adsorption of bovine serum albumin by liposomes, International Journal of Pharmaceutics, 32 (1986) 237-241.

[41] B. Misme-Aucouturier, M. Albassier, N. Alvarez-Rueda, P. Le Pape, Specific Human and Candida Cellular Interactions Lead to Controlled or Persistent Infection Outcomes during Granuloma-Like Formation, Infection and Immunity, 85 (2017) e00807-00816. 
620 [42] C.D. Pfeiffer, G.P. Samsa, W.A. Schell, L.B. Reller, J.R. Perfect, B.D. Alexander, 621 Quantitation of Candida CFU in Initial Positive Blood Cultures, Journal of Clinical 622 Microbiology, 49 (2011) 2879-2883.

6

7

623

10

11

12

13

14

15

16

17

18

19

20

21

22

23

24

25

26

27

28

29

30

31

32

33

34

35

36

37

38

39

40

41

42

43

44

45

46

47

48

49

50

51

52

53

54

55

56

57

58

59

60

61 


\section{Tables}

1

2

625 Table 1. Levels and factors investigated with the sample and separate setup for the release 626 studies of AmB from Ambisome ${ }^{\circledR}$ in clinically relevant media.

\begin{tabular}{|c|c|c|c|}
\hline Level & BSA \%w/v & Medium & Agitation (rpm) \\
\hline-1 & 2.0 & PBS BS 19.8 mM PL 7.9 mM & 130 (Low Agitation) \\
\hline+1 & 4.0 & KRB BS 20.0 mM PL 4.0 mM & 380 (High Agitation) \\
\hline
\end{tabular}


Table 2. PK-Sim model set up: physicochemical properties, distribution and clearance parameters of "released AmB" and "liposomal AmB" $\left(\right.$ Ambisome $\left.^{\circledR}\right)$ after administration to healthy subjects.

\begin{tabular}{|c|c|}
\hline \multicolumn{2}{|r|}{ "Released AmB" } \\
\hline Molecular weight (g/mol) & $924[29,30]$ \\
\hline $\log \mathbf{P}$ & 0.80 [29], 0.94 [31], 1.84 [31], 2.14 [31] \\
\hline $\operatorname{clog} \mathbf{P}$ & - 2.33 [29], - 0.66 [29], 1.16 [32] \\
\hline pka & acidic 5.5 [30], basic $10.0[30]$ \\
\hline Solubility at $\mathrm{pH}=7$ & $0.09 \mu \mathrm{g} / \mathrm{mL}[33], 1.38 \mu \mathrm{g} / \mathrm{mL}[34], 6.00 \mu \mathrm{g} / \mathrm{mL}[35]$ \\
\hline fraction unbound (albumin) & $0.05[28]$ \\
\hline Distribution volume & $2340 \pm 202 \mathrm{~mL} / \mathrm{kg}[27]$ \\
\hline Cl renal & $0.07 \pm 0.01 \mathrm{~mL} / \mathrm{min} / \mathrm{kg}$ [27]. GFR fraction $=0.875$ \\
\hline $\mathbf{C l}$ biliary & $0.09 \pm 0.02 \mathrm{~mL} / \mathrm{min} / \mathrm{kg}$ [27]. $\mathrm{k}_{\text {bil }}=0.002 \mathrm{~h}^{-1}$ \\
\hline
\end{tabular}




\begin{tabular}{|c|c|}
\hline \multirow[t]{2}{*}{ Binding partners } & $\begin{array}{l}\text { alfa } 1 \text { acid glycoprotein (AAG1), EST expression, } \mathrm{k}_{\mathrm{diss}}=1.07-2.44 \mu \mathrm{mol} / \mathrm{L} \text { (approximation from unbound } \\
\text { fraction) [27] }\end{array}$ \\
\hline & beta lipoprotein (APOB), EST expression, $\mathrm{k}_{\text {diss }}=0.25 \mu \mathrm{mol} / \mathrm{L}[36]$ \\
\hline \multicolumn{2}{|l|}{ "Liposomal AmB" } \\
\hline Distribution volume & $1628 \pm 876 \mathrm{~mL} / \mathrm{kg}[27]$ \\
\hline Cl renal & $0.01 \pm 0.00 \mathrm{~mL} / \mathrm{min} / \mathrm{kg}$ [27], GFR fraction $=0.125$ \\
\hline Cl biliary & $0.01 \pm 0.00 \mathrm{~mL} / \mathrm{min} / \mathrm{kg}[27], \mathrm{k}_{\mathrm{bil}}=0.0003 \mathrm{~h}^{-1}$ \\
\hline \multicolumn{2}{|r|}{ Assumptions for the model, considering the "liposomal AmB" as a molecule } \\
\hline Molecular weight (g/mol) & 924 \\
\hline Radius (solute) & $80 \mathrm{~nm}[37]$ \\
\hline $\log \mathbf{P}$ & Parameter to identify, starting value 0.8 \\
\hline pka & Neutral \\
\hline
\end{tabular}




\begin{tabular}{|c|c|}
\hline Solubility at $\mathbf{p H}=7$ & $\begin{array}{l}290 \mathrm{mg} / \mathrm{mL} \text { [calculated from the total amount of powder in a formulation vial }(14.5 \mathrm{~g}) \text {, dissolved in } 50 \mathrm{~mL} \\
\text { of water] }\end{array}$ \\
\hline fraction unbound albumin & 0.05 \\
\hline 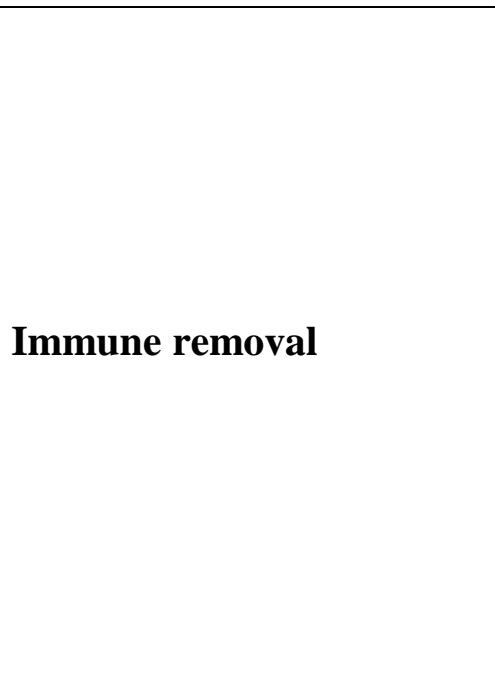 & $\begin{array}{l}\text { Metabolizing enzymes -> Intrinsic clearance First order -> } \\
\text { Relative expression -> Intracellular -> Endosomal } \\
\text { Plasma } \\
\text { Liver periportal } \\
\text { Liver pericentral } \\
\text { Spleen } \\
\text { S } \\
\text { S }\end{array}$ \\
\hline
\end{tabular}


Table 3. Parameters and the range in which the parameters were investigated in the sensitivity analysis of the validated PBPK model of Ambisome ${ }^{\circledR}$ administration.

\begin{tabular}{|c|c|c|}
\hline Parameter & Abbreviation & Interval tested \\
\hline log P ("liposomal AmB") & $\log \mathrm{P}(\operatorname{lip})$ & $0-2$ (log units) \\
\hline $\log \mathrm{P}$ ("released AmB") & $\log \mathrm{P}(\mathrm{rel})$ & $2.24-4.24$ (log units) \\
\hline $\begin{array}{l}\text { Aqueous solubility ("liposomal } \\
\text { AmB") }\end{array}$ & Sol (lip) & $90-490(\mu \mathrm{g} / \mathrm{mL})$ \\
\hline Aqueous solubility ("released AmB") & Sol (rel) & $0.01-6.00(\mu \mathrm{g} / \mathrm{mL})$ \\
\hline Radius solute ("liposomal AmB") & Rad (lip) & $40-120(\mathrm{~nm})$ \\
\hline $\mathrm{k}_{\mathrm{bil}}$ ("liposomal AmB") & Bil (lip) & $0.0001-0.0005\left(\mathrm{~h}^{-1}\right)$ \\
\hline $\mathrm{k}_{\text {bil }}($ "released AmB") & Bil (rel) & $0.001-0.003\left(h^{-1}\right)$ \\
\hline GFR ("liposomal AmB") & GFR (lip) & $0-1$ (fraction) \\
\hline GFR ("released AmB") & GFR (rel) & $0-1$ (fraction) \\
\hline "Immune enzyme" specific clearance & Imm & $1.57-3.57\left(\mathrm{~h}^{-1}\right)$ \\
\hline APOB $1 k_{d i s s}$ & APOB1 & $0.12-0.37(\mu \mathrm{mol} / \mathrm{L})$ \\
\hline AAG1 $k_{\text {diss }}$ & AAG1 & $0.21-0.63(\mu \mathrm{mol} / \mathrm{L})$ \\
\hline$k_{\text {rel-iv }}$ & krel & $0.114-3.539\left(\mathrm{~h}^{-1}\right)$ \\
\hline $\begin{array}{l}\text { Unbound fraction ("liposomal } \\
\qquad \mathrm{AmB} ")\end{array}$ & fU (lip) & $0.05-0.95$ (fraction) \\
\hline
\end{tabular}




\begin{tabular}{|c|c|c|c|c|c|}
\hline KRB & 4.0 & BS 20.0 mM PL 4.0 mM & HA & $0.896 \pm 0.041$ & $88.141 \pm 2.480$ \\
\hline \multicolumn{7}{|c|}{ Continuous flow } \\
\hline KRB & 0.0 & BS 20.0 mM PL 4.0 mM & LV & $0.305 \pm 0.071$ & $49.181 \pm 17.119$ \\
\hline KRB & 4.0 & BS 20.0 mM PL 4.0 mM & LV & $0.467 \pm 0.162$ & $43.101 \pm 10.563$ \\
\hline KRB & 0.0 & BS 20.0 mM PL 4.0 mM & HV & $1.364 \pm 1.890$ & $60.416 \pm 4.593$ \\
\hline KRB & 4.0 & BS 20.0 mM PL 4.0 mM & HV & & - \\
\hline
\end{tabular}


Table 5. Properties of liposomes obtained from atomic force microscopy from the samples prepared in media with BS PL in the presence and absence of BSA. Mean \pm SD. $n=20$ Random Particles.

\begin{tabular}{|l|c|c|c|}
\hline Sample & Diameter & Surface & Density \\
& $(\mathbf{n m})$ & Roughness $(\mathbf{n m})$ & $\left.\mathbf{( \mu m}^{-2}\right)$ \\
\hline KRB control (centrifugation/vacuum) & $69.4 \pm 18.9$ & $12.9 \pm 1.6$ & 11.9 \\
\hline KRB BS 20.0 mM PL 4.0 mM & $130.0 \pm 13.0$ & $10.1 \pm 2.7$ & 7.7 \\
\hline KRB BS 20.0 mM PL 4.0 mM BSA 4.0\% & \multicolumn{3}{|c|}{ No Particles } \\
\hline
\end{tabular}

Table 6. Parameters obtained after fitting (Equation 6) of CFU time profiles from time killing experiments in KRB BSA 2 and 4\% w/v using different concentrations of AmB (0.75, 1.5 and $3.0 \mu \mathrm{g} / \mathrm{mL})($ Mean $\pm \mathrm{SD}, \mathrm{n}=2)$.

\begin{tabular}{|c|c|c|c|c|c|}
\hline $\begin{array}{c}\text { BSA } \\
(\% \mathrm{w} / \mathrm{v})\end{array}$ & $\begin{array}{c}\text { AmB } \\
(\mu \mathrm{g} / \mathrm{mL})\end{array}$ & $\% \boldsymbol{C F} \boldsymbol{U}_{\max }$ & $k_{k i l l}\left(\mathbf{h}^{-1}\right)$ & $\mathbf{R}^{2}$ & AIC \\
\hline \multirow{3}{*}{2.0} & 0.75 & $105.1 \pm 5.23$ & $0.33 \pm 0.03$ & $0.86 \pm 0.02$ & $52.88 \pm 0.3$ \\
\hline & 1.50 & $110.65 \pm 4.17$ & $0.54 \pm 0.03$ & $0.93 \pm 0.05$ & $47.16 \pm 6.17$ \\
\hline & 3.00 & $110.6 \pm 5.37$ & $0.77 \pm 0.11$ & $0.92 \pm 0.05$ & $48 \pm 6.43$ \\
\hline \multirow{3}{*}{4.0} & 0.75 & $101.75 \pm 4.6$ & $0.11 \pm 0.01$ & $0.89 \pm 0.01$ & $47.25 \pm 2.38$ \\
\hline & 1.50 & $123.8 \pm 10.04$ & $0.17 \pm 0.03$ & $0.84 \pm 0.07$ & $54.71 \pm 5.18$ \\
\hline & 3.00 & $107.65 \pm 6.15$ & $0.37 \pm 0.01$ & $0.9 \pm 0$ & $50.27 \pm 1.06$ \\
\hline
\end{tabular}




\section{Figure captions}

Figure 1. Workflow for the PBPK modeling of "liposomal AmB" and "released AmB" after the administration of Ambisome ${ }^{\circledR}$ to healthy subjects

Figure 2. Workflow for the PBPK-PD modeling of the liposomal and released AmB after the administration of Ambisome ${ }^{\circledR}$ to a hypoalbuminaemic population in order to simulate the pharmacological activity of the released AmB on C. albicans.

Figure 3. \% AmB released with the a) sample and separate and the b) continuous flow setup at $37{ }^{\circ} \mathrm{C}$ to investigate the effect of the type of buffer, the BSA $4.0 \% \mathrm{w} / \mathrm{v}$ presence and the hydrodynamics in clinically relevant media with BS - PL. (Mean \pm SD, $n=3$; solid lines: media with BSA $4.0 \% \mathrm{w} / \mathrm{v}$; dotted lines: media without BSA $4.0 \% \mathrm{w} / \mathrm{v})$.

Figure 4. Pareto charts for the estimated effects of the main factors and 2 level interactions of the analysis of a) $\% A m B_{\text {released }} \max$ and $k_{\text {rel }}$ from the sample and separate setup and b) the $A U C_{0-12 h}$ from the continuous flow method. A factor was significant when the estimated effect (horizontal bars) was larger than the standardized effect (vertical line).

Figure 5. AFM images to evaluate the effect of media components on Ambisome ${ }^{\circledR}$ liposomes. a) KRB BS 20.0 mM PL 4.0 mM, b) KRB BS 20.0 mM PL 4.0 mM BSA 4.0\% w/v. The scale bar represents $200 \mathrm{~nm}$.

Figure 6. Observed and simulated (PBPK model) plasma concentration profiles of "liposomal AmB" and "released AmB" after the administration of Ambisome ${ }^{\circledR}$ to healthy subjects $[25,26]$.

Figure 7. Sensitivity analysis of PBPK model parameters on the "liposomal AmB" and "released $\mathrm{AmB} " A U C_{0-24 h}$ obtained from simulated plasma concentrations in healthy subjects. The black line is the $A U C_{0-24 h}$ obtained from the validated PBPK model for healthy subjects. 
Figure 8. $A U C_{0-24 h}$ calculated from simulated plasma concentration profiles with with the model for "liposomal AmB" and "released AmB". $\mathrm{n}=5$ subjects for each population.

Figure 9. PBPK-PD model for a hypoalbuminaemic population (plasma protein fraction 0.5; healthy subjects: plasma protein fraction 1.0) -Simulated concentration and its pharmacodynamic effect on fungal cells. a) Simulated plasma concentration profiles of "liposomal AmB" and "released AmB" from the validated PBPK model for healthy subjects and the hypothesised model for the hypoalbuminaemic population, b) simulation of plasma concentrations following administration of a $300 \mathrm{mg}$ dose of Ambisome ${ }^{\circledR}$, c) simulated time killing rate coefficient $\left(k_{\text {kill }}\right)$ (corresponding to the simulated plasma concentration profile of Figure 9b), and d) effect of the administration of Ambisome ${ }^{\circledR}$ on the growth of Candida albicans. 


\section{"L.jposomal AmB"}

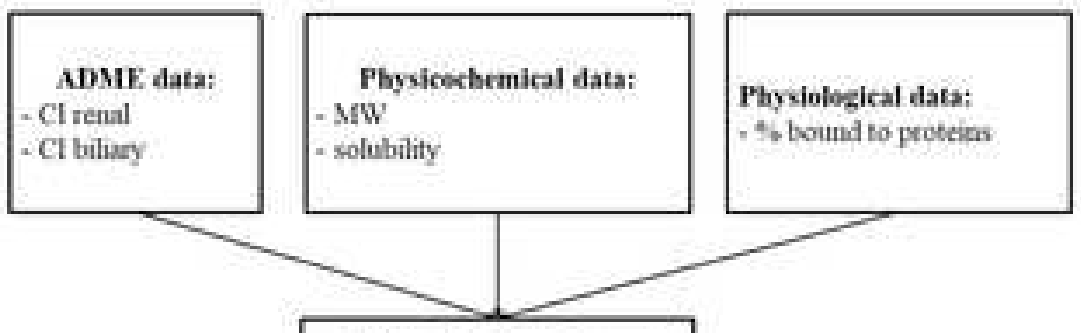

Initial model for hiposomal AmB
"Released AmB"

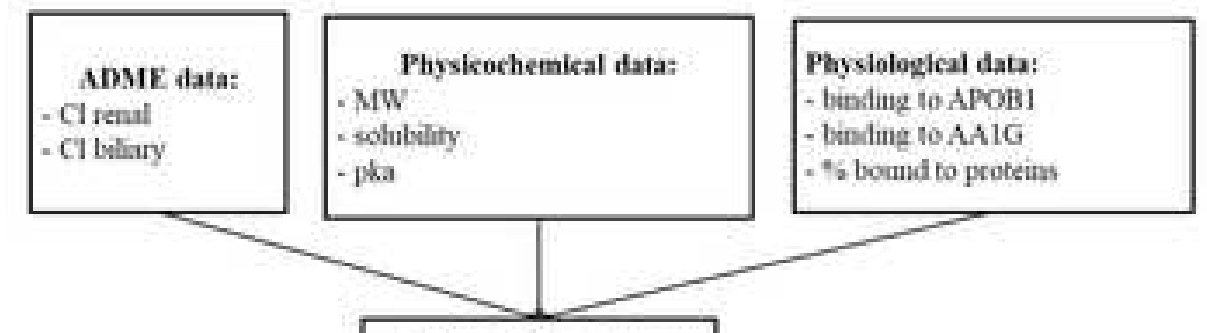

Lnitial model for relcased $\mathrm{AmB}$

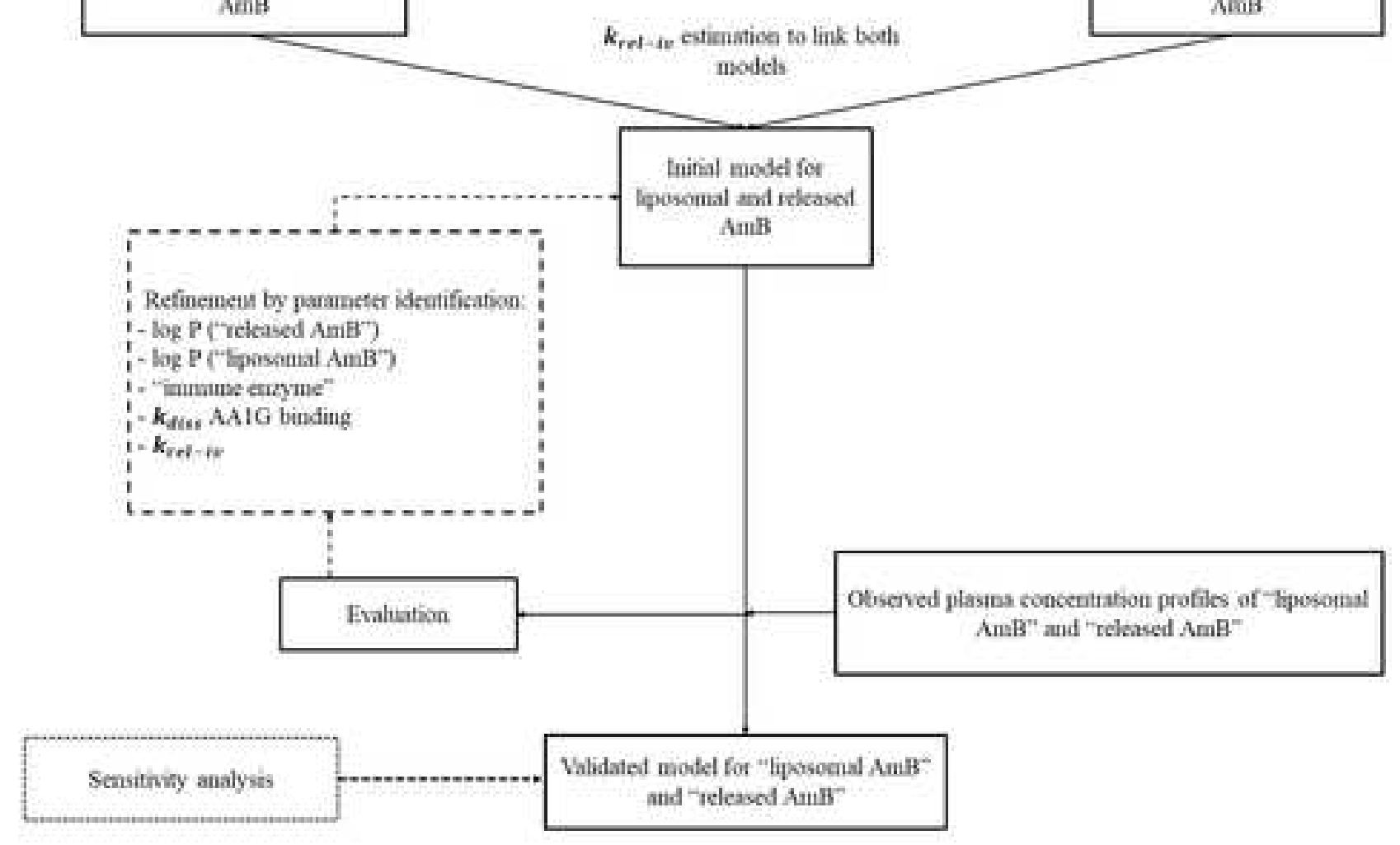


Evaluated PBPK model for liposomal and released $\mathrm{AmB}$ after $\mathrm{Ambisome} \otimes$ administration

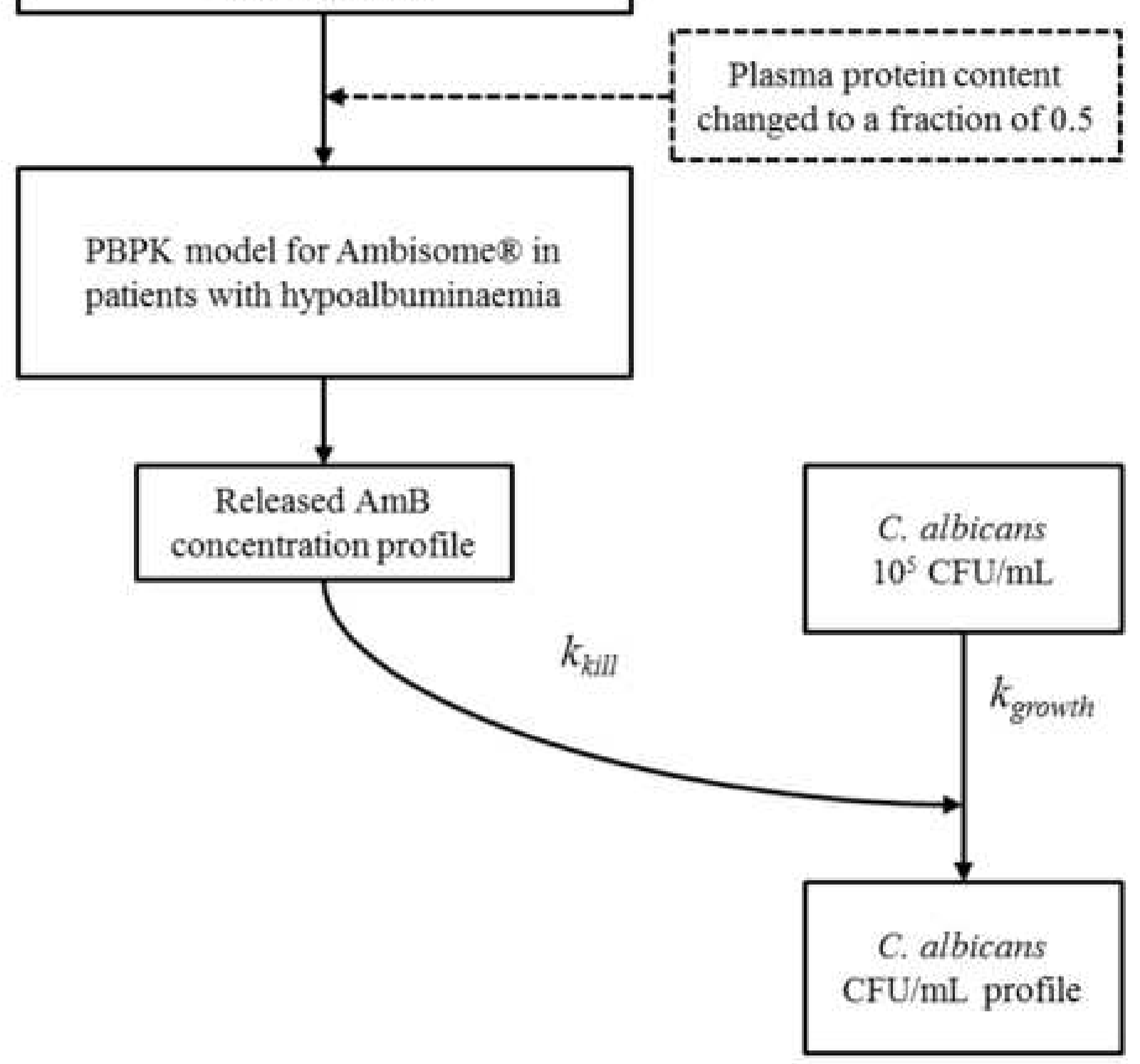


a)

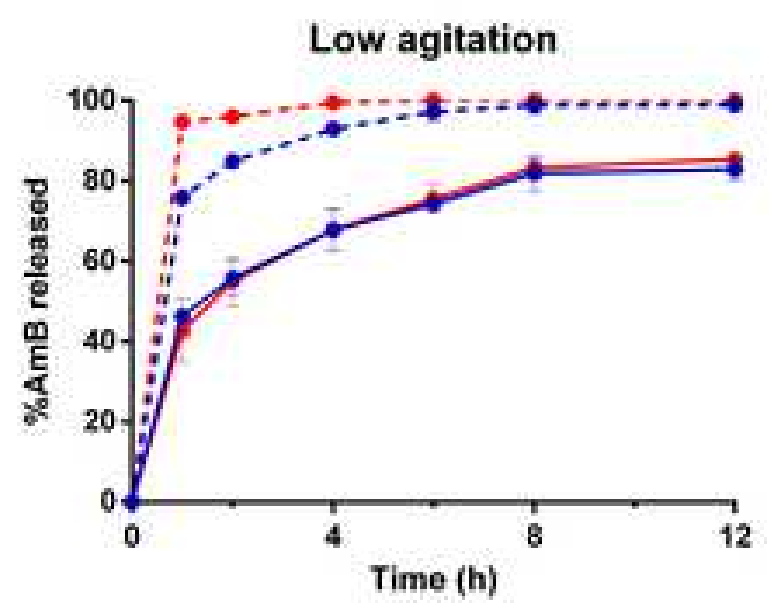

b)

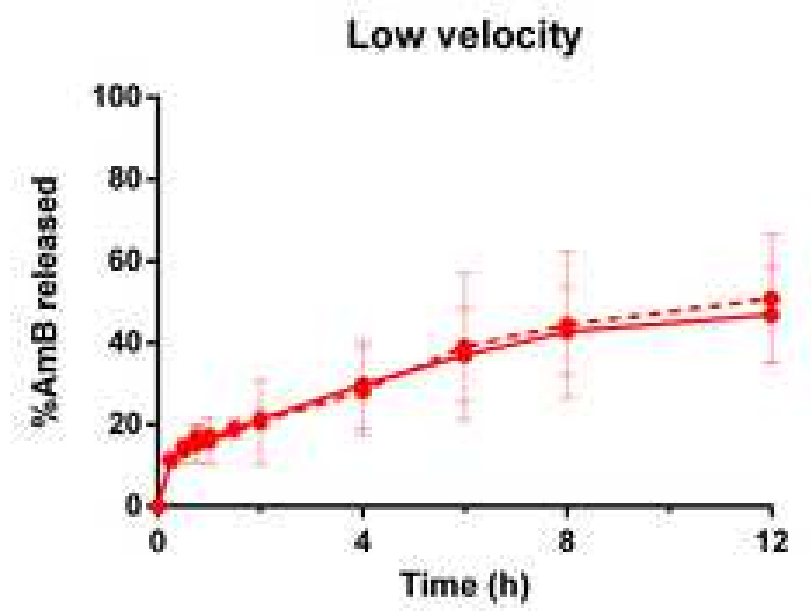

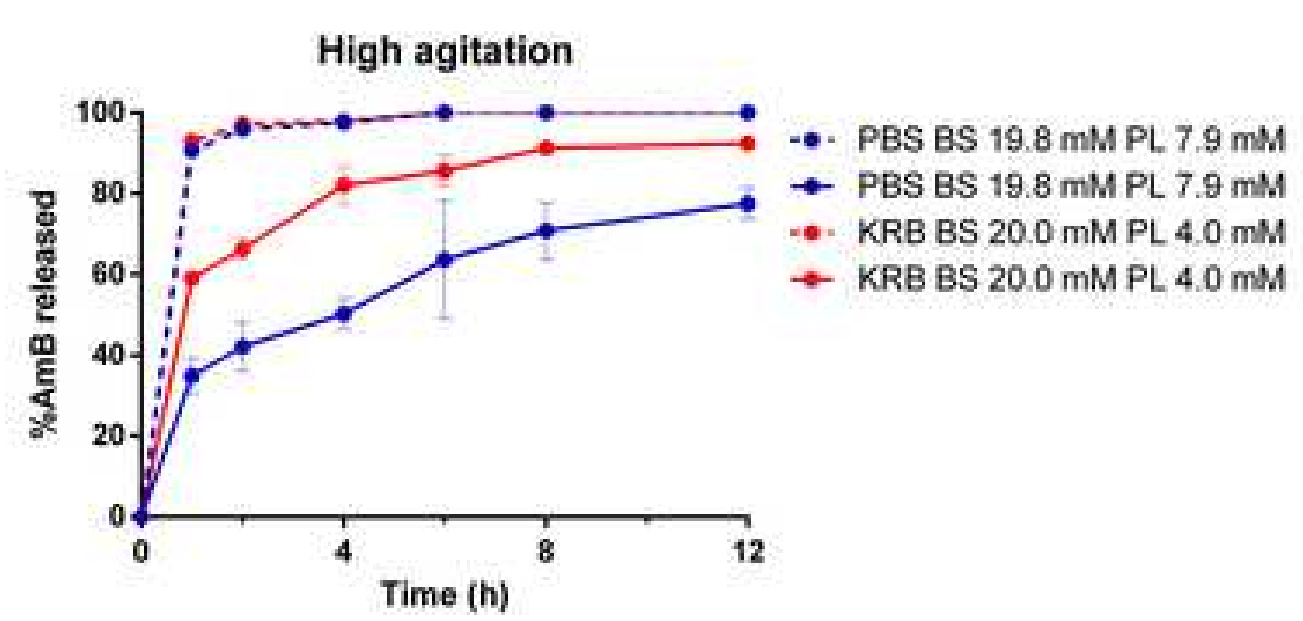

High velocity

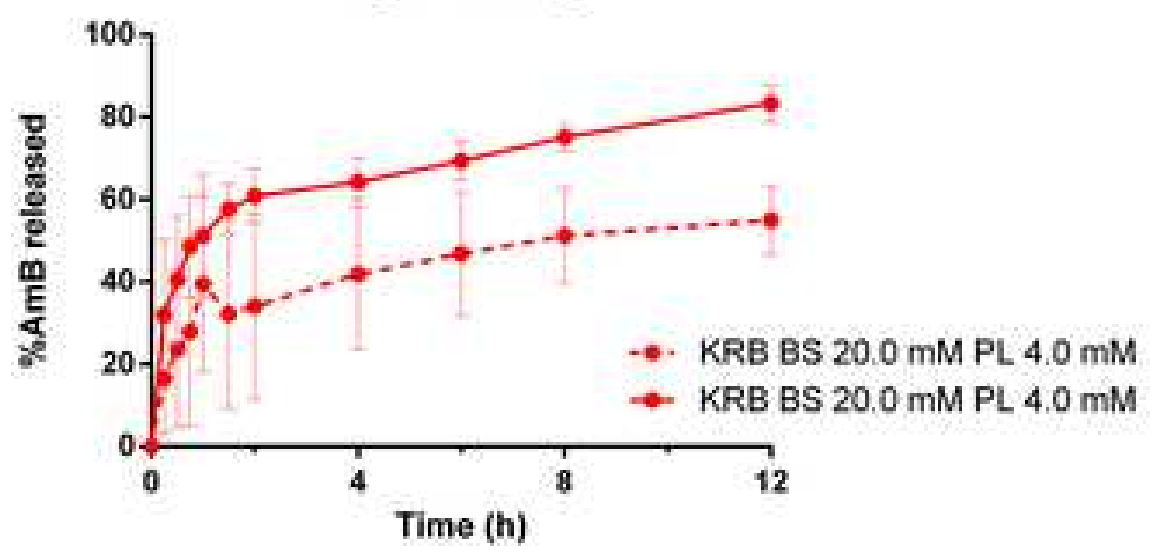


a)

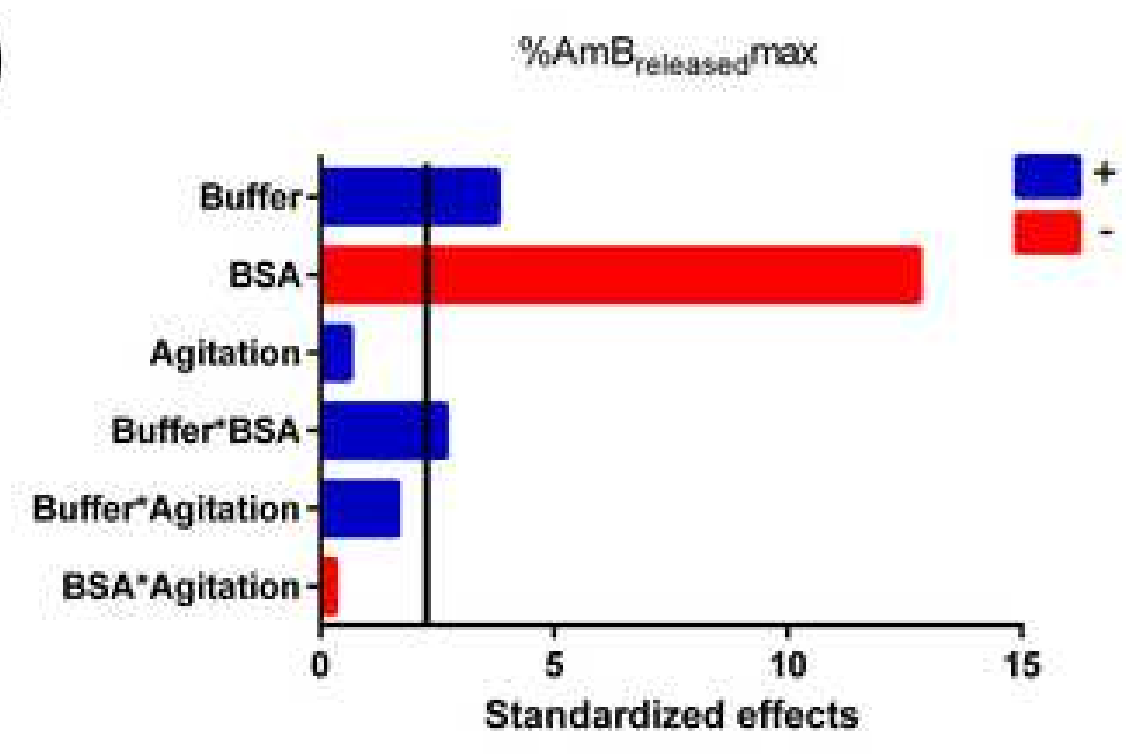

b)

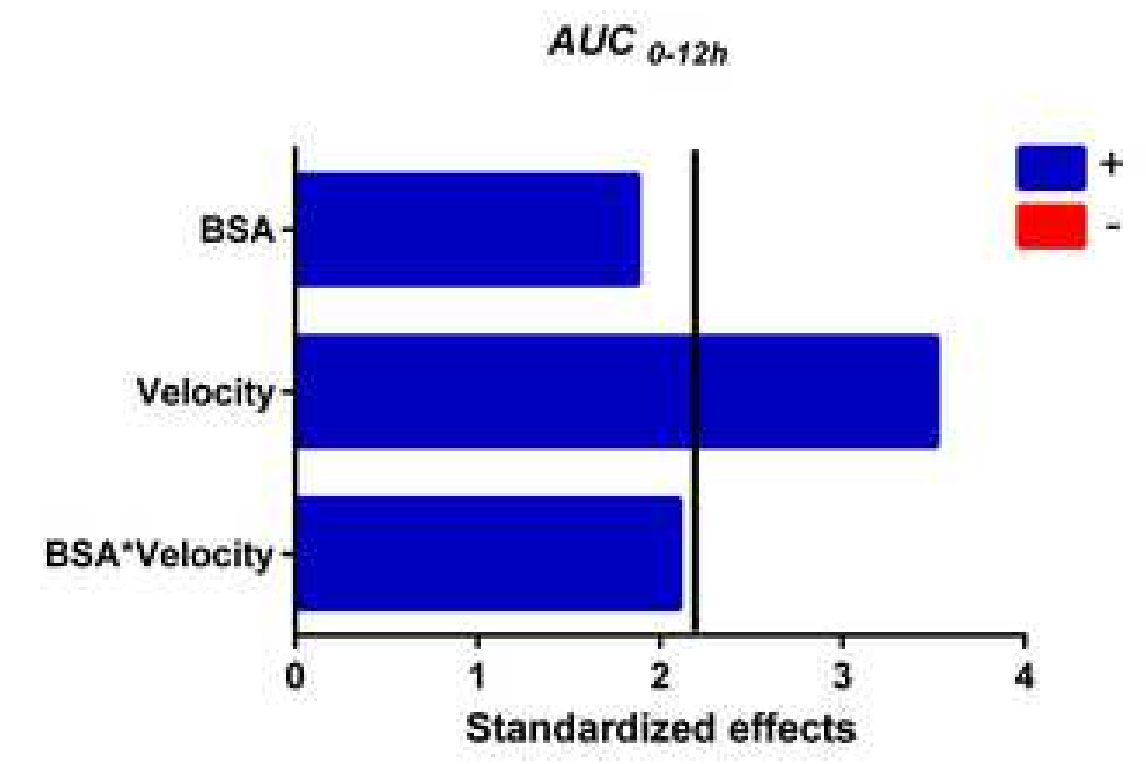

$$
k_{\text {rel }}\left(h^{-1}\right)
$$

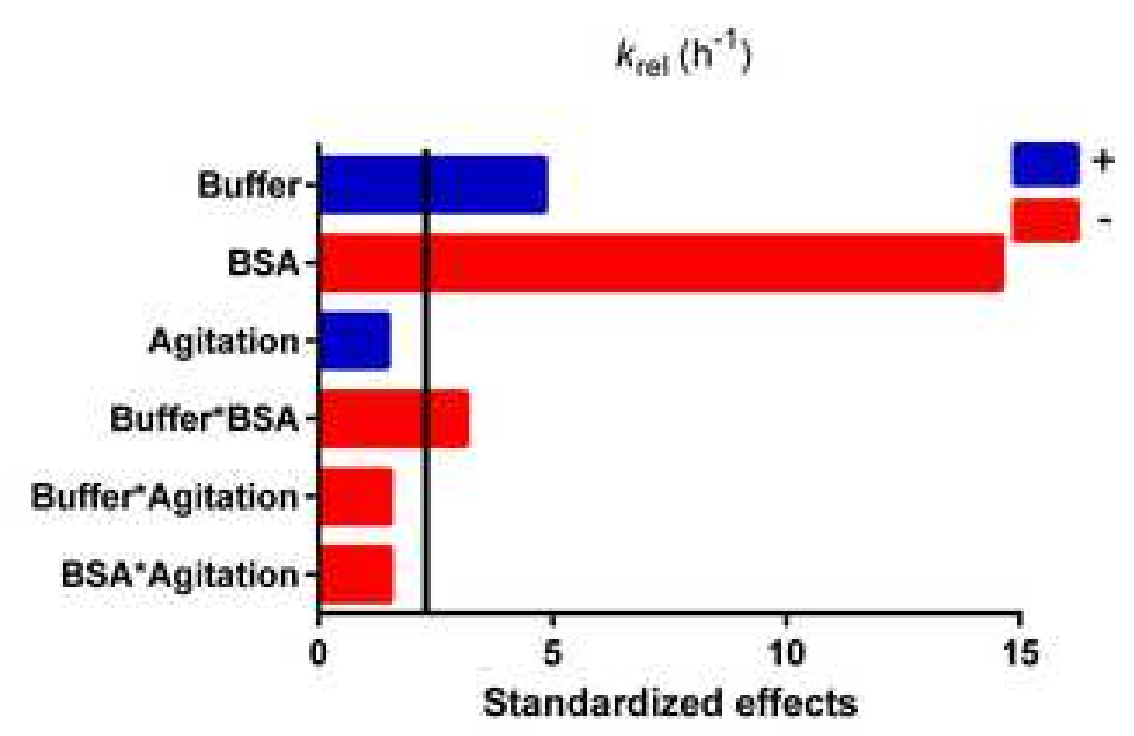

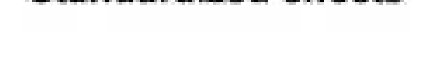
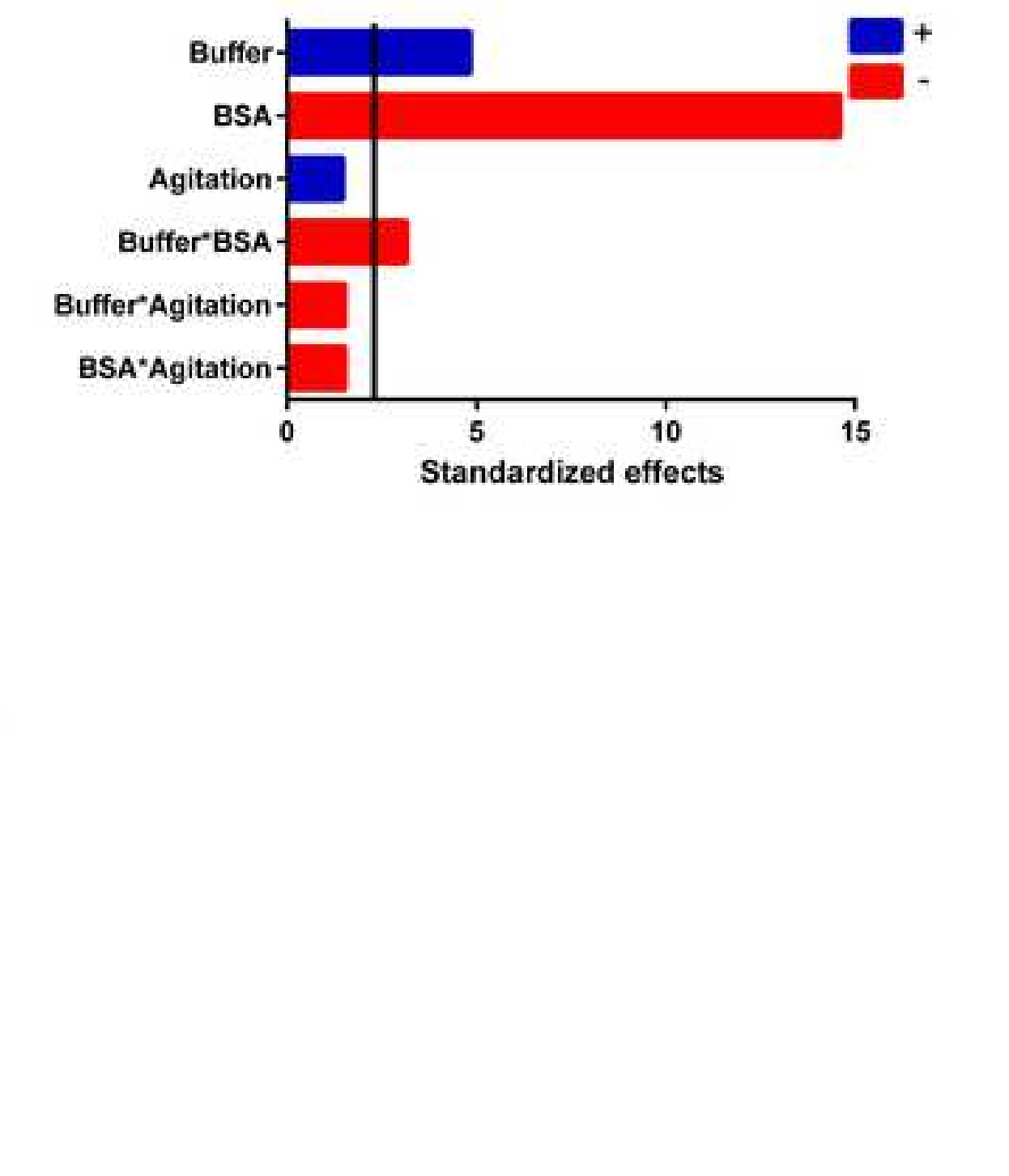

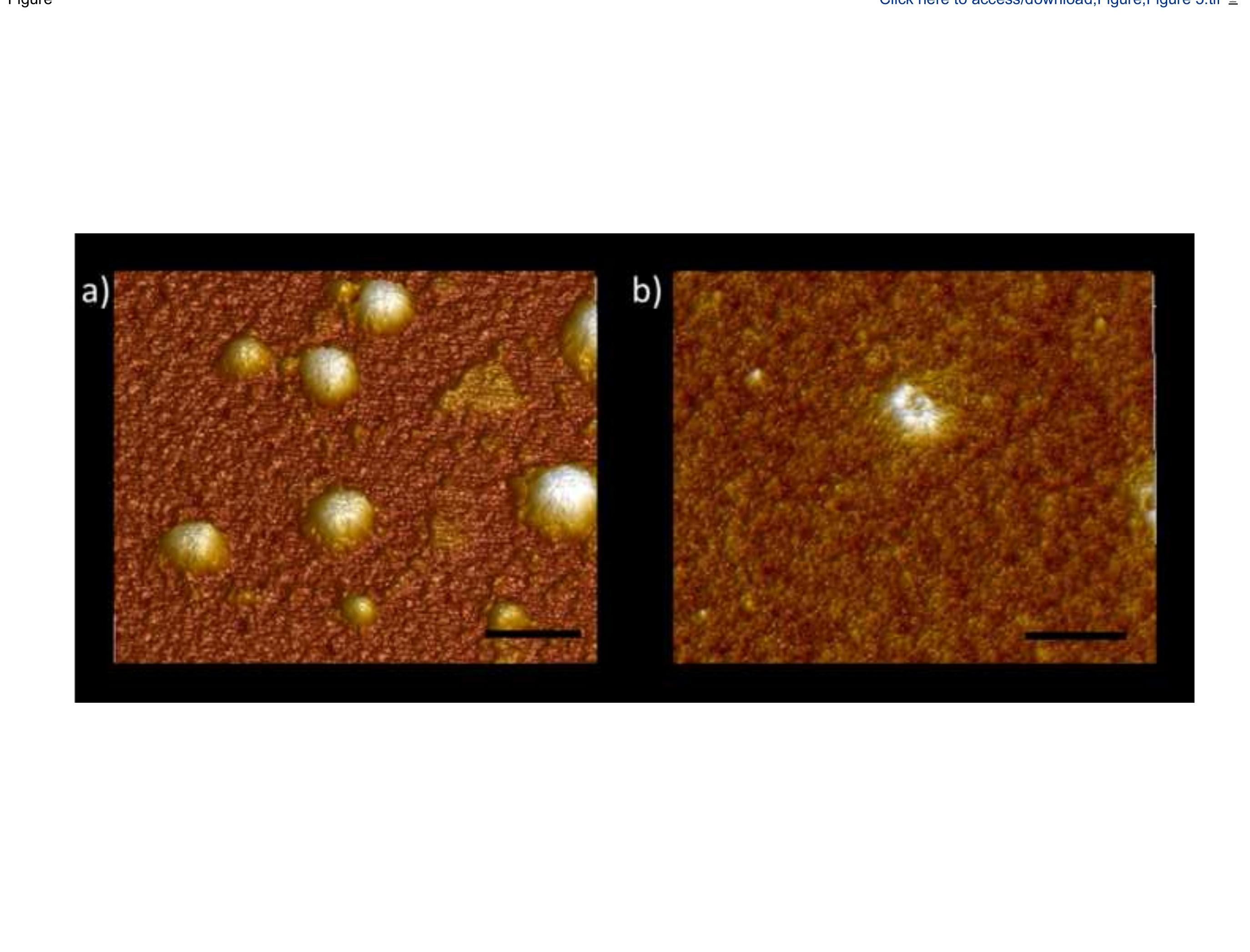


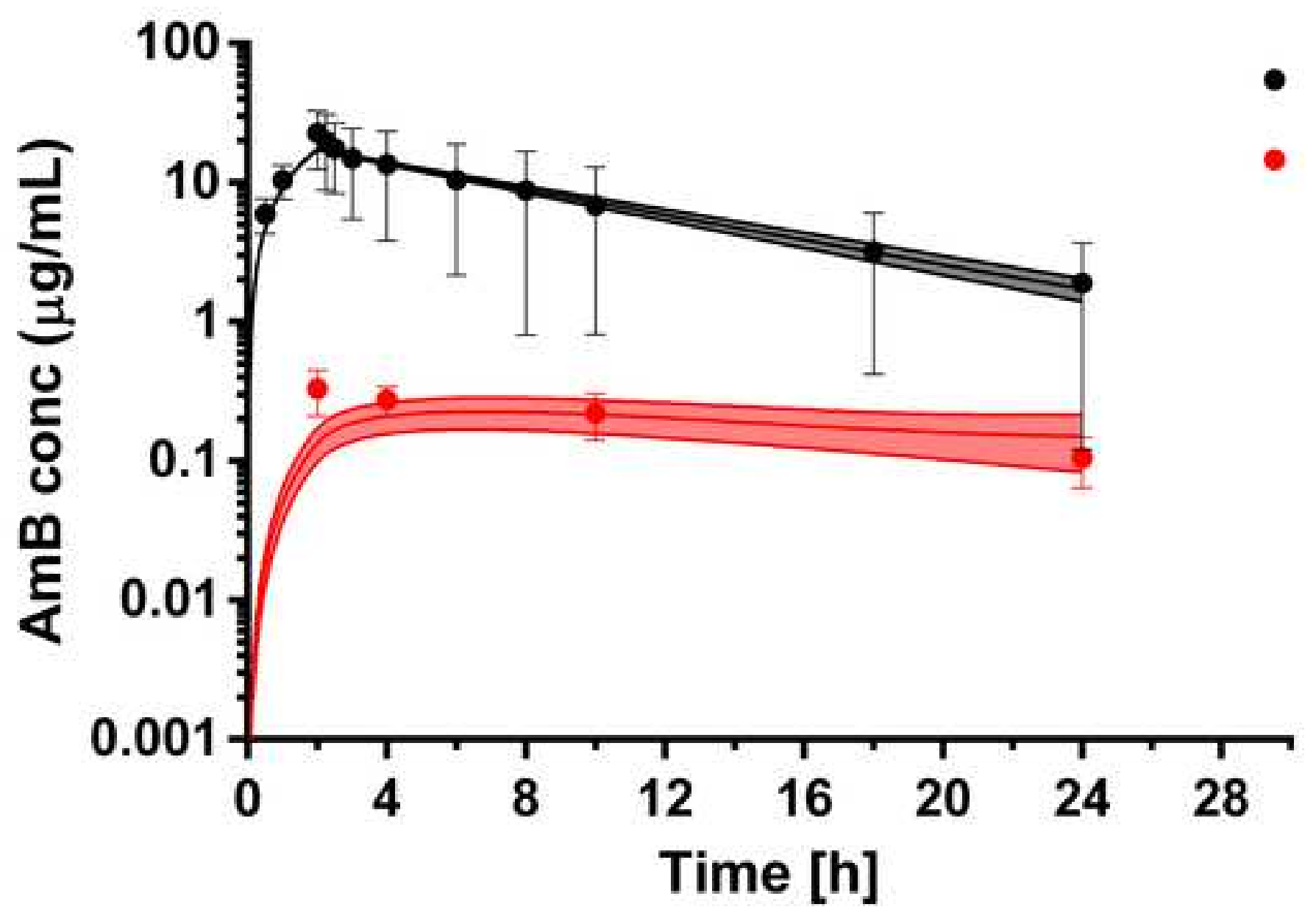

Liposomal AmB

- Released AmB 

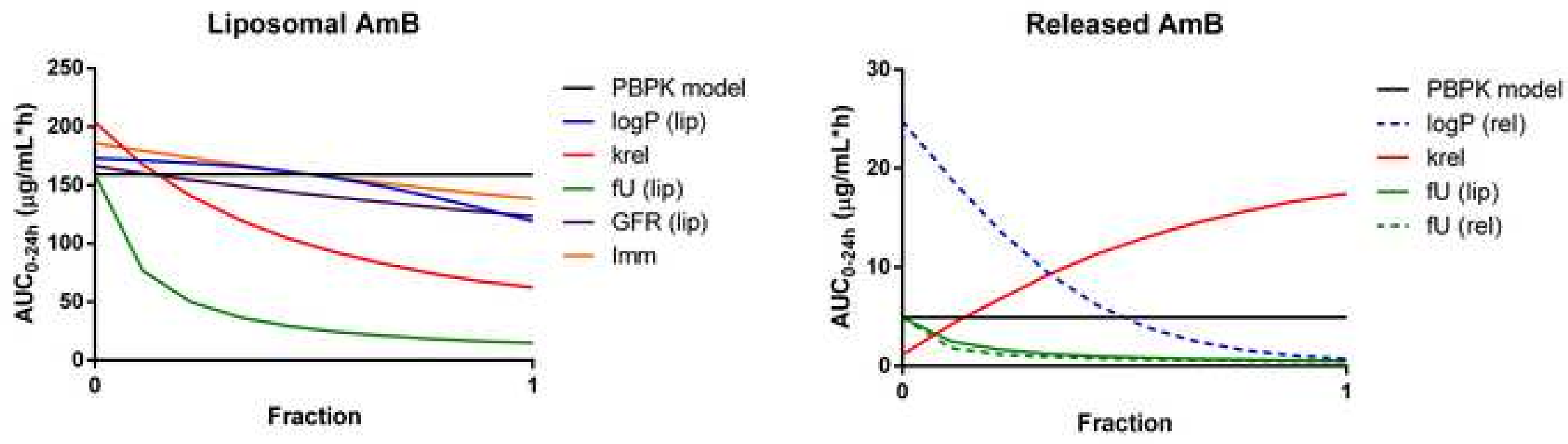
Lip AmB AUC $0.24 \mathrm{~h}$

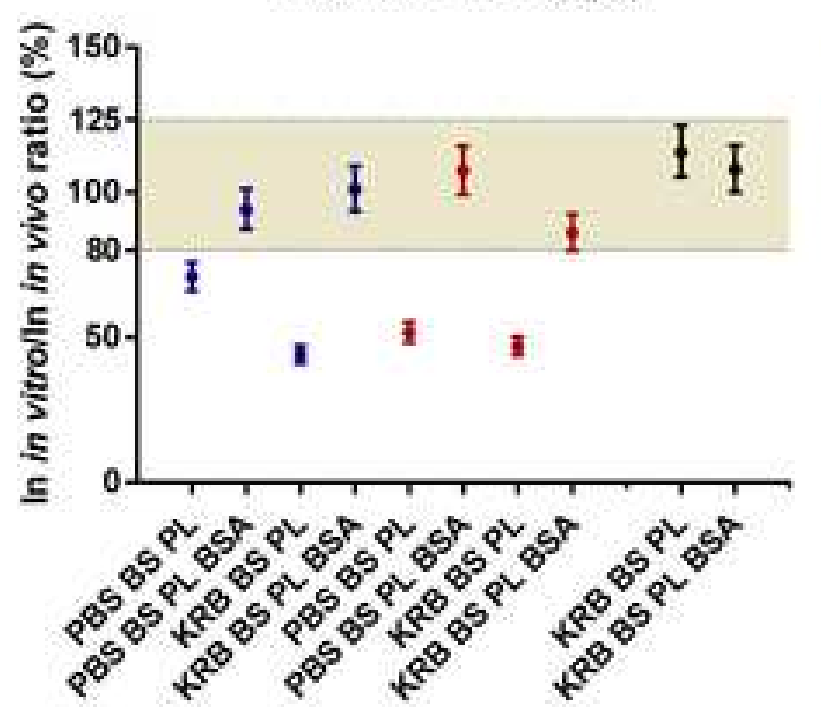

$\operatorname{Rel}$ AmB AUC . $24 h_{h}$

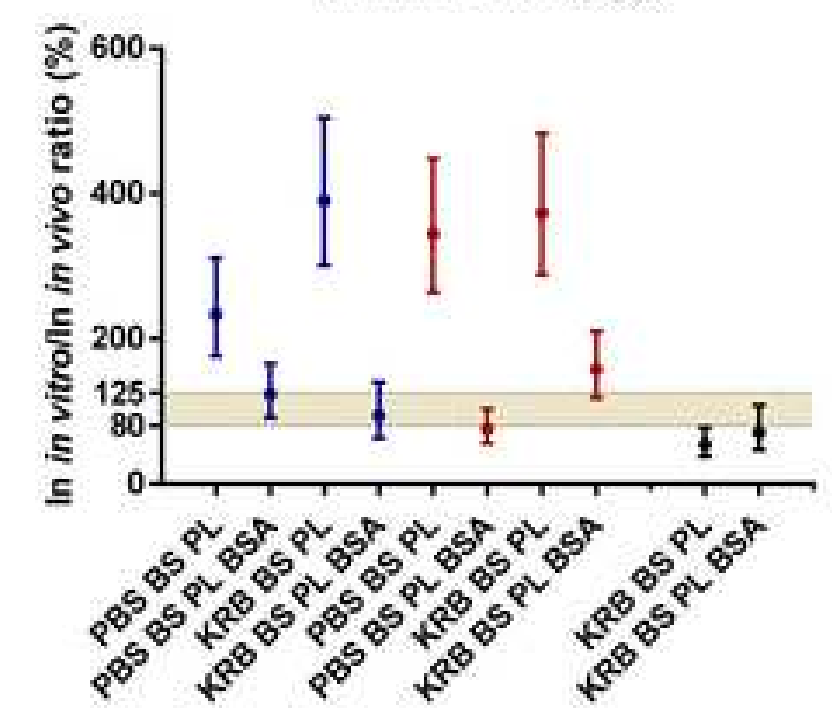

- Low agitation

- High agitation

- Low velocity
- High agitation

- Low velocity

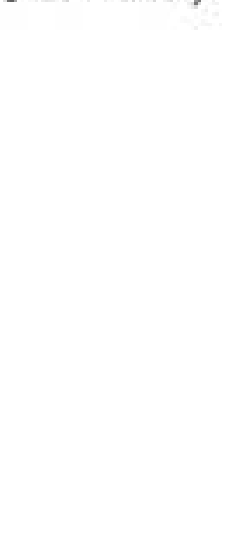


a)

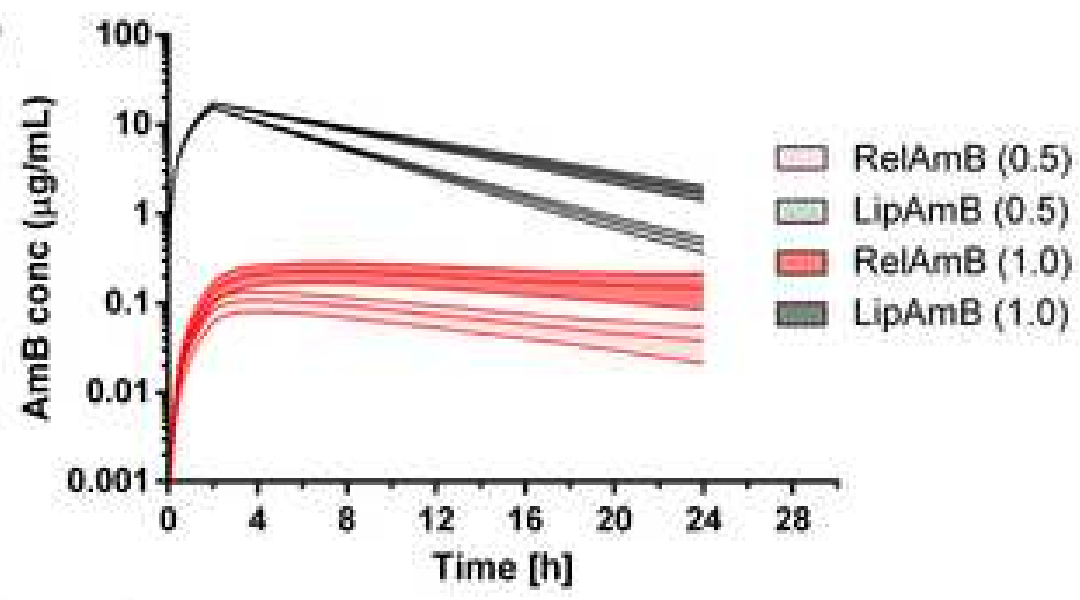

c)

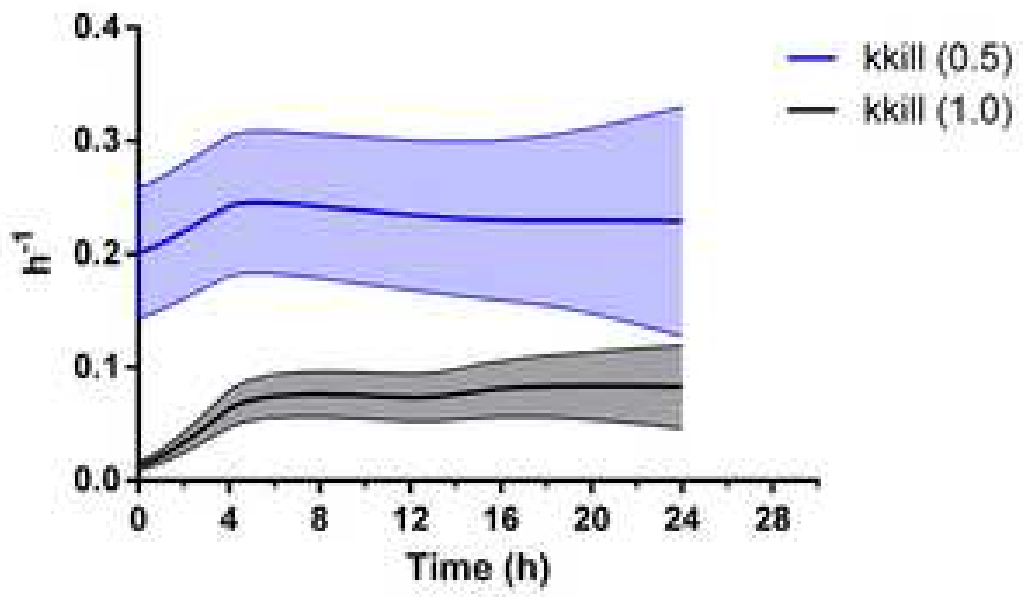

b)

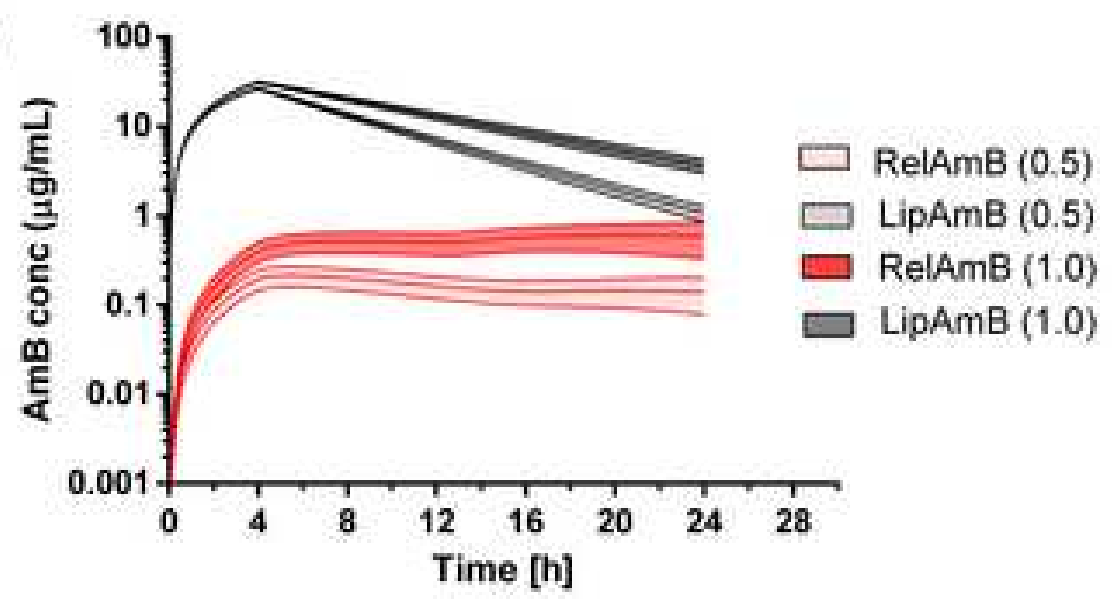

d)

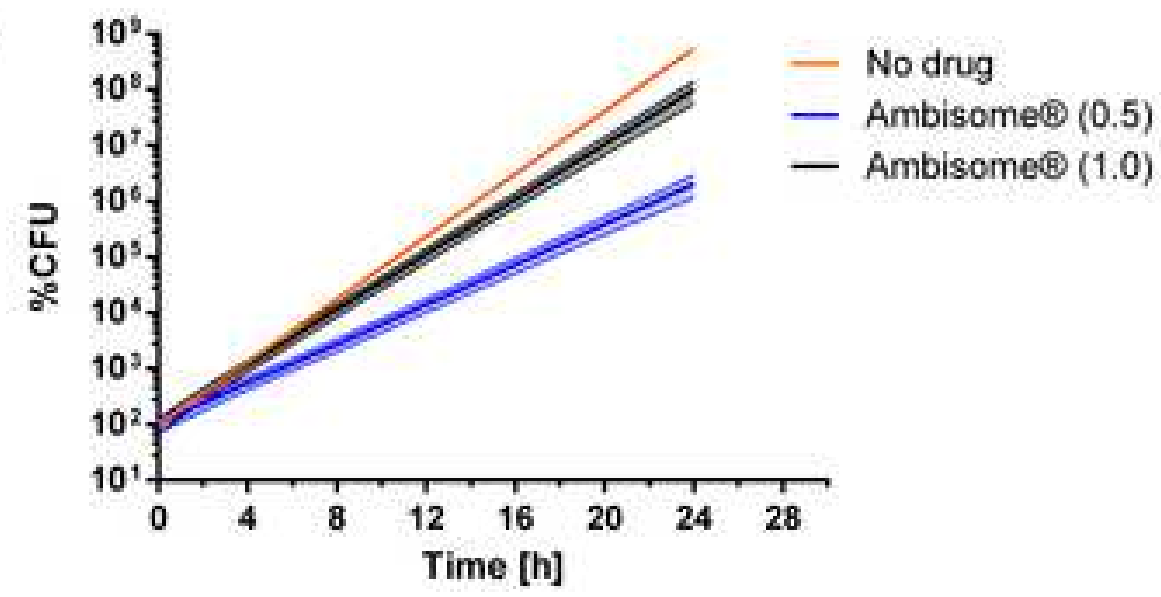

